\title{
AMBIENTALIZAÇÃO CURRICULAR DO ENSINO SUPERIOR: A LICENCIATURA EM ENFERMAGEM VETERINÁRIA DA ESCOLA SUPERIOR AGRÁRIA DE BRAGANÇA
}

EDUCATION FOR SUSTAINABILITY IN UNIVERSITY STUDIES: THE VETERINARY NURSING DEGREE AT THE AGRARIAN SCHOOL OF BRAGANÇA AMBIENTALIZACIÓN CURRICULAR DE LOS ESTUDIOS SUPERIORES: LA LICENCIATURA EN ENFERMERÍA VETERINARIA DE LA ESCUELA SUPERIOR AGRARIA DE BRAGANÇA

Alda Matos (alda@ipb.pt)*

\section{RESUMO}

No ensino superior a ambientalização dos cursos é residual. Segundo a documentação consultada, ainda que existam instituições com modelos de gestão ambiental mais eficientes, verificam-se lacunas no âmbito das suas funções básicas: docência, investigação e extensão. Tornou-se assim pertinente elaborar um estudo, elegendo uma licenciatura (Enfermagem Veterinária) numa instituição de ensino superior (Escola Superior Agrária de Bragança - ESAB), com o objetivo de observar se são incluídas temáticas ambientais no ensino-aprendizagem. Foram utilizadas fontes de informação primária e secundária. No contexto da informação primária foram aplicados questionários (alunos do $3^{\circ}$ ano e docentes) e entrevistas (órgãos decisores) no ano letivo de 2011/12. Concluiu-se que a ESAB é uma instituição amiga do ambiente quanto à gestão de recursos. Todavia, embora tenha firmado acordos no âmbito da educação para o desenvolvimento sustentável, não realizou ainda um plano ajustado aos conteúdos programáticos dos cursos. A ambientalização curricular está presente no curso, sendo a maior força a 'Coerência e Reconstrução entre Teoria e Prática' e a maior fraqueza a 'Ordem Disciplinar: Flexibilidade e Permeabilidade'. Biofísica foi a disciplina que mais se afastou das expectativas dos alunos, que não entendem a relevância da mesma para a sua formação nem a sua relação com as outras disciplinas do curso.

Palavras-chave: Ambientalização Curricular; Desenvolvimento Sustentável; Educação Ambiental; Enfermagem Veterinária; Ensino Superior.

\begin{abstract}
In the higher education system, environmental awareness is residual. According to the research, although institutions may include the most efficient management models, deficits still exist in the basic functions of teaching, research and extension. This gap motivated the development of this study to analyze a graduate degree (Veterinary Nursing) in higher education (the Agrarian School of Bragança - ESAB), focusing on ways in which environmental topics have been included in the learning and teaching process. Primary and secondary sources of information were used from the 2011-12 academic year. Surveys were distributed to 3rd year students and teachers and members of the decision making board were interviewed. It was concluded that ESAB is an environment-friendly institution in erms of resource management. Nevertheless, and despite having signed agreements related to education for sustainability, plans for adjusting the contents of the courses have not been made. Education for sustainability is part of the course, particularly in terms of Coherence and Reconstruction of Theory and Practice but notably
\end{abstract}




\section{Egitania \\ $\mathrm{s}$ c i e $\Omega$ c i a}

weak in terms of Disciplinary Order: Flexibility and Permeability. Biophysics was the subject that that was furthest from the students' expectations because they cannot understand its relevance for their training and the relationship between this subject and the other subjects of their degree.

Keywords: Education for Sustainability; Sustainable Development, Environmental Education; Veterinary Nursing, Higher Education.

\section{RESUMEN}

En la educación superior la ambientalización de los cursos es residual. Según la bibliografía consultada, aunque haya instituciones con modelos de gestión ambiental más eficiente, hay lagunas en las funciones básicas: docencia, investigación y extensión. Resulta así pertinente, la realización de una investigación, analizando una licenciatura (Enfermería Veterinaria) en una institución de Educación Superior (Escuela Superior Agraria de Bragança - ESAB) para ver si las cuestiones ambientales se incluyen en la enseñanza-aprendizaje. Se utilizaron fuentes primarias (encuestas a los alumnos de $3^{\circ}$ año y al profesorado y entrevistas a los órganos decisorios de la institución) y secundarias de información, durante el año académico de 2011/12. Se concluye que la ESAB es una institución amiga del ambiente en la gestión de recursos. Todavía, a pesar de haber firmado acuerdos de educación para la sostenibilidad, no ha puesto en práctica un plan curricular ajustado a los contenidos programáticos de los cursos. La ambientalización curricular está presente en el curso. La característica que obtuvo una puntuación mayor fue la coherencia entre teoría y práctica y la peor fue el orden disciplinar: flexibilidad y permeabilidad. Biofísica fue la aignatura que más se apartó de las expectativas de los alumnos, que no entienden su importancia para la formación y la relación con las otras asignaturas del curso.

Palabras-llave: Ambientalización Curricular; Desarrollo Sostenible, Educación Ambiental, Enfermería Veterinaria; Estudios Superiores.

\footnotetext{
* Professora Adjunta da Escola Superior Agrária do Instituto Politécnico de Bragança, Portugal. Membro do Departamento de Ciências Sociais e Exatas Doutorada em Educação Ambiental pela Universidade de Salamanca.
} 


\section{Egitania \\ s c i e $\Omega$ c i a}

\section{INTRODUÇÃO}

Desde a década de 70 do século passado que, devido aos excessos do sistema industrial, a sociedade vem tomando consciência da crise socioambiental.

As causas mais associadas a esta crise foram o crescimento populacional, a produção e consumo excessivos (com a deficiente evacuação de resíduos) e a desigualdade na distribuição da riqueza. Estes fatores provocaram desequilibrios naturais e sociais por todo o mundo.

De facto, a crise atual resulta de diversas grandes crises globais. A primeira, foi a crise sociodemográfica. Em 1900 contavam-se 1,65 mil milhões de habitantes no planeta. Atualmente, a população mundial mais que quadruplicou e os consumos industriais multiplicaram-se. No entanto, não quadruplicaram os recursos naturais. Passou-se assim a uma segunda crise, a crise ambiental, sustentada na escassez dos recursos.

No âmbito do aumento demográfico e da superprodução, os países foram atribuindo diferentes respostas às mesmas questões e instalou-se a polaridade nos dois hemisférios. Nos países do Norte surgiram os problemas de obesidade e nos países do Sul os problemas de desnutrição. Naturalmente que a terceira crise transportou consigo a pobreza versus riqueza, já que a distribuição dos recursos e dos rendimentos à escala global se efetuou de forma desigual.

A quarta crise é uma crise territorial e, portanto, cultural, e surge na sequência da anterior, em que os povos migram em busca de melhor qualidade de vida. A troca de culturas, principalmente nas grandes cidades, acarreta convulsões sociais e governamentais, porque já não são as leis nacionais que regulam os países, mas as leis transnacionais ou regionais.

A estas crises junta-se uma mudança do paradigma tecnológico - a sociedade do conhecimento - e para culminar, dá-se uma mudança no paradigma científico, absolutamente crucial, e que poderá, se utilizado de modo consciente, dar resposta a algumas das crises aqui focadas. Embora a sociedade tenha seguido os percursos da especialização técnica ou científica, tomou-se consciência que a essência do Desenvolvimento Sustentável - DS se encontra na interdisciplinaridade. Este novo paradigma impõe às equipas de especialistas uma mudança de atitude na resolução das questões atuais.

O desenvolvimento sustentável tem acompanhado estas crises e transportado algumas respostas para a qualidade do ambiente, as prioridades sociais dos povos e uma nova ética de comportamento humano. Estas respostas focalizam-se nas necessidades das populações, sem comprometer os ecossistemas, a dinâmica natural que lhes dá suporte e a disponibilidade futura dos recursos naturais.

A Educação Ambiental - EA veio a constituir-se como uma das estratégias inquestionáveis para o cumprimento dos princípios de desenvolvimento sustentável, por permitir o contacto direto dos cidadãos comuns na resolução dos problemas locais/globais.

Todavia, para se tomarem decisões coerentes e sustentáveis é necessária uma formação sistémica, ética e comprometida com a promoção de um desenvolvimento humano integral e sustentável, consolidada e assente numa visão de futuro. 
O ensino superior é considerado por diversos autores (Weenen, 2000; Rychen e Salganik, 2003; Fouto, 2002; Cachapuz et al., 2003; Martins et al., 2003; Junyent et al., 2003; Geli et al., 2003, 2004; Couto et al., 2004, 2005, 2006; Hidalgo, 2007; Barth et al., 2007; Madeira, 2008; Martínez, 2008; Minguet e Solis, 2009; Marcomin e Silva, 2009; Barrón et al., 2010; Murga-Menoyo, 2013; entre tantos outros), o órgão de excelência para responder a este desafio.

Assim, desde o impacto provocado pelo Relatório Brundtland, em 1987, as Instituições do Ensino Superior - IES têm-se envolvido em parcerias internacionais e assinado declarações de compromisso para o fomento da Educação para o Desenvolvimento Sustentável - EDS. Contudo, tem sido visível no contexto mundial que, embora as IES se encontrem altamente especializadas nas ciências, estão debilmente preparadas para formar os alunos de acordo com uma perspetiva ética, globalizante e interdisciplinar. Tanto mais que as organizações mundiais advertem para a mudança de mentalidades e de comportamentos no ensino superior, pois são estas instituições que preparam o maior número de pessoas que gerem as instituições públicas e privadas, tendo ainda a indispensável função da produção e difusão do conhecimento e dos valores para a sociedade.

No ensino superior português a ambientalização dos cursos é igualmente residual. Embora se tenham incorporado modelos de gestão mais eficientes, persistem deficiências na aplicação global e articulada da sustentabilidade, designadamente na docência, na investigação e na extensão (Fouto, 2002 e Couto et al., 2004; 2005; 2006).

Foi neste quadro que algumas IES encetaram um processo de reflexão e investigação, para a geração de conhecimentos científicos e culturais, no sentido de exercerem uma função de liderança no processo de construção de uma educação para o desenvolvimento sustentável.

De facto, a introdução da sustentabilidade nos politécnicos e universidades veio responder à pressão sentida no ensino superior europeu pelos discursos neoliberais de sujeição do setor às condições atuais dos mercados, relegando para segundo plano os seus objetivos e missões. Tanto mais que os sinais sobre a dinâmica interdisciplinar na investigação e no ensinoaprendizagem, no âmbito de um modelo de instituição sustentável, evidenciam ainda um estado embrionário de produção e partilha de conhecimento com a sociedade.

Assim, considerando estas debilidades, tornou-se pertinente elaborar um trabalho de investigação (estudo de caso), abordando um curso de licenciatura (Enfermagem Veterinária) numa instituição de ensino superior (Escola Superior Agrária do Instituto Politécnico de Bragança), tendo como finalidade analisar em que medida são incorporadas temáticas ambientais no processo de ensino-aprendizagem ${ }^{1}$.

Quanto à organização do estudo, apresentam-se de seguida os objetivos, a metodologia e as hipóteses de investigação. Seguidamente, faz-se uma breve apresentação da Escola Superior

1 Este trabalho teve como base a tese de doutoramento: Matos, A. (2014) A Sustentabilidade Curricular da Licenciatura em Enfermagem Veterinária da Escola Superior Agrária de Bragança - Portugal. Universidade de Salamanca. Espanha. 
Agrária de Bragança e da licenciatura em Enfermagem Veterinária - EV. Finalmente, apresentamse os resultados da investigação e tecem-se algumas conclusões e recomendações.

\section{OBJETIVOS, METODOLOGIA E HIPÓTESES DE INVESTIGAÇÃO}

O objetivo desta investigação é analisar em que medida a Sustentabilidade Curricular SC (ou Ambientalização Curricular) está contida no ensino-aprendizagem da licenciatura em Enfermagem Veterinária da Escola Superior Agrária de Bragança.

Assim, metodologicamente, a investigação dividiu-se em duas partes. Na primeira enquadramento teórico - foi efetuada a análise de conteúdo da informação secundária. Na segunda - estudo empírico - foi efetuada a análise de conteúdo de documentos institucionais e análise e tratamento da informação primária (questionários e entrevistas).

Na recolha da informação primária foram administrados questionários mistos (questões abertas e questões fechadas) aos docentes do curso de Enfermagem Veterinária e aos alunos do $3^{\circ}$ ano do mesmo curso. Foram ainda realizadas entrevistas formais aos indivíduos que desempenharam papéis relevantes nos processos de discussão, implementação e organização do curso: Presidente do Conselho Cientifico, simultaneamente Diretor da ESAB, Vice-Presidente do Conselho Pedagógico, Diretora da Comissão de Curso, Coordenador do Departamento de Ciência Animal, um elemento da Comissão de Constituição do Curso e um Informante-chave (Tabela 1).

\begin{tabular}{|c|c|c|c|}
\hline Respondentes & $\begin{array}{l}\text { Técnica de } \\
\text { Recolha de } \\
\text { Dados } \\
\end{array}$ & $\begin{array}{c}\text { Guião de } \\
\text { Entrevista/Inquérito }\end{array}$ & Total \\
\hline $\begin{array}{c}\text { Presidente do Conselho Científico } \\
\text { Diretor da Escola Superior }\end{array}$ & \multirow{5}{*}{ Entrevista Formal } & \multirow{5}{*}{ Questões abertas } & 1 \\
\hline $\begin{array}{c}\text { Vice-Presidente do Conselho } \\
\text { Pedagógico }\end{array}$ & & & 1 \\
\hline Diretora da Comissão de Curso & & & 1 \\
\hline $\begin{array}{c}\text { Coordenador do Departamento } \\
\text { de Ciência Animal }\end{array}$ & & & 1 \\
\hline Comissão de Constituição do Curso & & & 1 \\
\hline Informante-chave & Entrevistas & $\begin{array}{c}\text { Semi-estruturadas ou } \\
\text { espontâneas }\end{array}$ & 1 \\
\hline $\begin{array}{c}\text { Docentes do curso de Enfermagem } \\
\text { Veterinária }\end{array}$ & \multirow{2}{*}{ Questionário Misto } & \multirow{2}{*}{$\begin{array}{l}\text { Questões fechadas } \\
\text { Questões abertas }\end{array}$} & 16 \\
\hline $\begin{array}{l}\text { Alunos do } 3^{\circ} \text { ano do curso de } \\
\text { Enfermagem Veterinária }\end{array}$ & & & 29 \\
\hline \multicolumn{3}{|c|}{ Total } & 51 \\
\hline
\end{tabular}

Tabela 1 - Sintetização das fontes de informação primária

No que respeita aos alunos, selecionou-se uma amostra representativa da população, com uma dimensão de 29 alunos, com base no total de estudantes (Tabela 2) matriculados no $3^{\circ}$ ano do curso de Enfermagem Veterinária, no ano letivo de 2011/2012. 


\begin{tabular}{|l|c|c|c|}
\hline \multirow{2}{*}{ População Alvo } & $3^{\circ}$ Ano & \multicolumn{2}{|c|}{ Amostra } \\
\cline { 3 - 5 } & $\left(\mathbf{n}^{\circ}\right)$ & $\left(\mathbf{n}^{\circ}\right)$ & $(\%)$ \\
\hline Alunos do Curso de EV & 47 & 29 & 62 \\
\hline Docentes do Curso de EV & 20 & 16 & 80 \\
\hline Total & 67 & 45 & \\
\hline Dirigentes & - & 5 & - \\
\hline Informante-chave & - & 1 & - \\
\hline Total & 67 & 51 & - \\
\hline
\end{tabular}

Tabela 2 - Constituição da amostra

Nesse mesmo ano encontravam-se matriculados 131 estudantes no curso de EV, 23 dos quais no $1^{\circ}$ ano, 61 no $2^{\circ}$ ano e 47 no $3^{\circ}$ ano. Apenas se administraram inquéritos aos alunos do $3^{\circ}$ ano, por se encontrarem na fase final da sua formação e, portanto, possuírem uma visão mais vasta e integral da Escola e do curso. De entre estes, selecionaram-se apenas os alunos que frequentaram regularmente as aulas ao longo dos cinco semestres da licenciatura (exclusão do semestre do estágio profissional).

Com vista a melhorar a qualidade e pertinência das questões propostas, no sentido da obtenção de informação concisa e rigorosa, foram administrados previamente, nove questionários aos alunos do $3^{\circ}$ ano. O pré-teste foi executado numa sala de aula, na ESAB, na presença da própria. Foram expostos os objetivos e a natureza da investigação, lido oralmente todo o questionário e explicadas as questões verbalmente antes do preenchimento. Optou-se por efetuar uma breve introdução oral sobre as dez componentes da rede ACES, já que se tornaria morosa e entediante para os alunos, a leitura prévia de um documento explicativo sobre as mesmas. Todo este processo teve a duração de duas horas.

O questionário sofreu algumas alterações após o pré-teste, ganhando em percetibilidade. As questões imprecisas ou de interpretações ambíguas foram reformuladas ou eliminadas. Esta fase foi crucial para a correção de outros aspetos relacionados com a terminologia do questionário. Após garantido o anonimato e a confidencialidade dos dados, o questionário definitivo foi administrado em janeiro de 2012 aos 29 alunos do $3^{\circ}$ ano, numa das salas de aula da ESAB, na presença da investigadora. Foram igualmente explicadas previamente as questões, as 10 componentes da rede ACES e esclarecidas algumas dúvidas durante o preenchimento do questionário.

Quanto aos docentes, foram realizados e validados 16 questionários.

Dos 20 questionários dirigidos ao total do corpo docente excluiu-se um, por se tratar da investigadora, e os restantes três não foram devolvidos pelos docentes ${ }^{2}$. Na seleção dos

2 A investigadora lecionou a unidade curricular de 'Organização e Gestão da Empresa' e os docentes referidos as UC de 'Anatomia', 'Nutrição Animal', 'Zootecnia Geral' e 'Enfermagem Veterinária'. 


\section{Egitania}

s c i e $\Omega$ c i a

professores esteve subjacente o critério da responsabilidade em lecionar disciplinas (partilhadas ou não) aos alunos da licenciatura em Enfermagem Veterinária, no ano letivo de 2011/2012.

Os questionários aos docentes foram igualmente validados por meio de um pré-teste administrado a dois docentes com experiência na área da investigação social. Em resultado reconheceu-se a necessidade de alterar a ordem de algumas questões, visando uma melhor contextualização do questionário e rigor nas respostas. Os inquéritos foram distribuídos e devolvidos pessoalmente, durante o segundo trimestre de 2012.

Toda a recolha de informação foi realizada pela investigadora.

Para superar algumas falhas de informação e melhor compreender determinados fenómenos, foi regularmente entrevistado um informante-chave do Departamento de Ciência Animal, durante o período de recolha da informação primária. De entre os docentes do departamento, foi selecionado o elemento que melhor fornecesse informações detalhadas sobre o departamento, o curso (estrutura curricular e funcionamento da atividade letiva) e os órgãos de decisão subjacentes. Assim, foi eleito um docente com uma longa carreira no Departamento de Ciência Animal e com um papel ativo e relevante nas atividades académicas.

O seu contributo na prestação pontual de informação foi imprescindível para consolidar a informação recolhida, constituindo-se como um elo de múltiplas questões que se nos colocaram no decorrer da investigação. Nestas entrevistas (espontâneas, baseadas num guião dinâmico), o processo de coleta de informação surgia casualmente no local de trabalho, onde os assuntos abordados, com interesse para a investigação, emergiam do diálogo e da relação de confiança entre entrevistadora e entrevistado.

O objetivo do questionário administrado aos alunos foi observar os seus conhecimentos sobre a problemática ambiental, as suas opiniões sobre a atividade docente e sobre as Unidades Curriculares - UC. O objetivo do questionário administrado aos docentes foi observar os seus conhecimentos sobre a problemática ambiental, sobre a ambientalização curricular no ensino superior e a sua dinâmica no processo de ensino-aprendizagem. O objetivo das entrevistas aos órgãos decisores foi complementar e interligar a informação anterior.

A partir de 2002 a rede de Ambientalização Curricular do Ensino Superior - ACES veio responder ao repto da sustentabilidade no ensino superior. Desenvolveu um modelo de 'Ambientalização Curricular', constituído por dez componentes e respetivos indicadores, no sentido de os adequar aos planos de estudo, ao ensino-aprendizagem, à investigação e extensão e à gestão das instituições.

Assim, toda a análise empírica teve como quadro teórico de referência o Marco Teórico ACES. Optou-se por esta metodologia por ser mais abrangente, sistémica e atual, por oferecer diferentes contributos a nível nacional e internacional e por ser ajustável a diferentes instituições. Deste modo, o modelo teórico ACES foi um instrumento de avaliação do curso, que possibilitou confrontar a veracidade das hipóteses de investigação. Foi igualmente um eixo orientador, que permitiu seguir uma trajetória passo a passo, segundo os princípios delineados e propostos pela rede ACES (Figura 1). 
No círculo intermédio da figura estão presentes as dez características da rede ACES e, em seu torno, os dezanove indicadores selecionados para o estudo da sustentabilidade curricular da licenciatura em EV.

Temos assim que, com base na informação primária e secundária, e de acordo com o marco teórico ACES, foi possível efetuar a análise da sustentabilidade curricular do curso (Figura 2).

No âmbito da investigação foram formuladas cinco hipóteses, que assentaram na lógica teórica da problemática de investigação. As hipóteses foram testadas pela triangulação da informação primária e secundária:

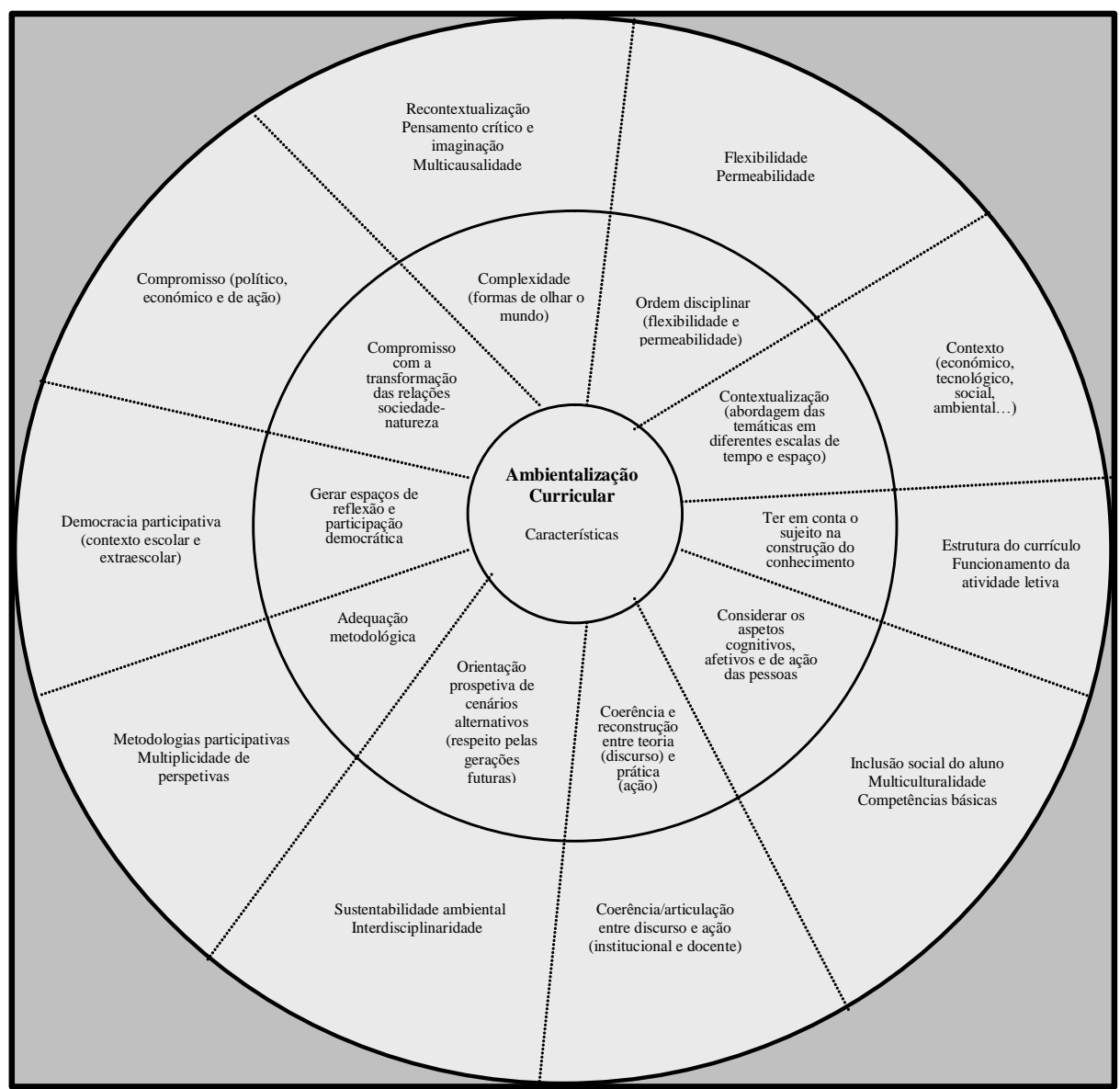

Figura 1 - Diagrama das dez características da rede ACES e dos indicadores selecionados para

a avaliação da sustentabilidade curricular do curso de Enfermagem Veterinária

Fonte: Elaboração própria, com base na Rede ACES, Mendoza, 2002, cit. por Júnior et al. (2003).

- Hipótese 1: A Escola Superior Agrária do Instituto Politécnico de Bragança, assumiu diversos compromissos internacionais, como o Programa de Bolonha e o Programa COPERNICUS ${ }^{3}$, para oferecer aos estudantes uma educação para o desenvolvimento

Cooperation Program for Environmental Research in Nature and Industry through Coordinated University Studies. Guidelines for Sustainable Development in the European Higher Education Area: How to incorporate the principles of sustainable development into the Bologna Process. 
sustentável, pelo que possui um plano de sustentabilidade curricular ajustado aos conteúdos programáticos dos cursos que leciona.

- Hipótese 2: Os docentes da licenciatura em Enfermagem Veterinária da ESAB estão preparados para lecionar segundo o processo de ensino-aprendizagem preconizado pelos programas de Bolonha e COPERNICUS (princípios de EDS).

-Hipótese 3: Os docentes são portadores de uma visão sistémica da realidade em conceitos como 'Ambiente' e 'Educação Ambiental para o Desenvolvimento Sustentável', que implica que durante a atividade de ensino-aprendizagem os problemas socioambientais sejam considerados na apresentação dos conceitos científicos.

- Hipótese 4: Os alunos do $3^{\circ}$ ano da licenciatura em Enfermagem Veterinária possuem uma visão sistémica da realidade, relativamente aos conceitos de 'Ambiente' e 'Desenvolvimento Sustentável'.

-Hipótese 5: O processo de ensino-aprendizagem da licenciatura em Enfermagem Veterinária é executado segundo as dez características preconizadas pela rede ACES.

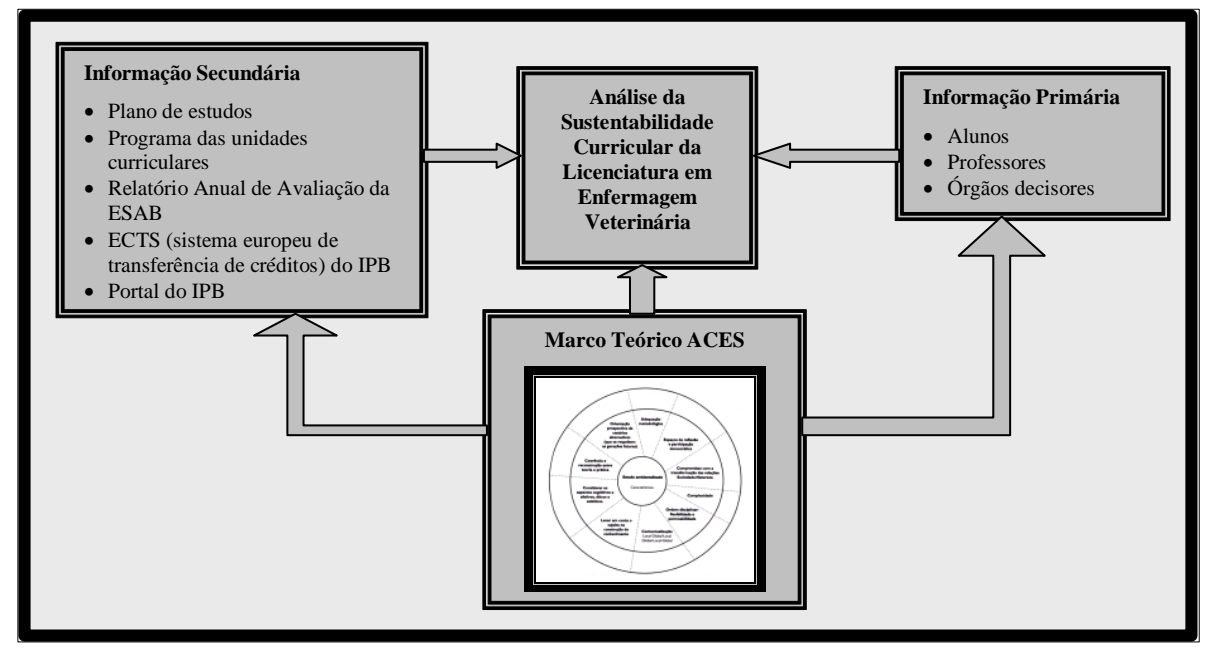

Figura 2 - Análise da sustentabilidade curricular da licenciałura em Enfermagem Veterinária

Para observar a literacia ambiental dos alunos e docentes foram construídas duas grelhas de análise (Tabelas 3 e 4).

A seleção dos tópicos de análise assentou na observação de diversos conceitos de 'Ambiente', a partir da sua conceção globalizadora, e do conceito de 'Desenvolvimento Sustentável', a partir dos indicadores de desenvolvimento sustentável aprovados pela Comissão de Desenvolvimento Sustentável - CDS das Nações Unidas. As componentes/dimensões de ambos os conceitos foram divididas em categorias e subcategorias, que nos permitiram comparar os resultados obtidos nos questionários. 


\begin{tabular}{|c|c|c|c|}
\hline \multicolumn{4}{|c|}{ Ambiente } \\
\hline \multirow{4}{*}{$\begin{array}{c}\text { Interação } \\
\text { entre as três } \\
\text { componentes, } \\
\text { como um } \\
\text { sistema } \\
\text { integral do } \\
\text { mundo e da } \\
\text { vida }\end{array}$} & Componentes & Categorias & Sub-categorias \\
\hline & $\begin{array}{l}\text { Ambiental Natural } \\
\text { ou Meio Físico } \\
\text { Natural (ambiente } \\
\text { no sentido estrito) }\end{array}$ & $\begin{array}{l}\text { Componentes } \\
\text { físicas e biológicas }\end{array}$ & $\begin{array}{l}\text { - ar } \\
\text { - águas } \\
\text { - terra, solo, subsolo } \\
\text { - fontes primárias de energia } \\
\text { - fauna, flora e diversidade genética } \\
\text { - processos ecológicos essenciais (fotossíntese, regeneração } \\
\text { natural...) } \\
\text { - clima, elementos e fatores que o determinam } \\
\text { - radiação solar } \\
\text { - cosmos }\end{array}$ \\
\hline & $\begin{array}{l}\text { Ambiente Social } \\
\text { (extensão cultural, } \\
\text { histórica, artística, } \\
\text { económica) }\end{array}$ & $\begin{array}{l}\text { Elementos } \\
\text { influenciados pelos } \\
\text { humanos }\end{array}$ & $\begin{array}{l}\text { - indivíduos e coletividades (classes, grupos, etnias, } \\
\text { instituiçães...) } \\
\text { - características sociodemográficas das populações (inter- } \\
\text { relações, valores, estruturas de poder, organização social, } \\
\text { manifestações culturais, problemas sociais, atividades } \\
\text { económicas, ciência e tecnologia...) }\end{array}$ \\
\hline & $\begin{array}{l}\text { Ambiente Construído } \\
\text { ou Meio Físico } \\
\text { Transformado }\end{array}$ & $\begin{array}{l}\text { Elementos espaciais } \\
\text { construídos pelos } \\
\text { humanos }\end{array}$ & $\begin{array}{l}\text { - formas e estruturas espaciais (estradas, acessibilidades, } \\
\text { espaços abertos, edifícios, infraestruturas, equipamentos, } \\
\text { serviços...) } \\
\text { - circuitos de relações (habitar, trabalhar, circular, recrear o } \\
\text { corpo e o espírito...) }\end{array}$ \\
\hline
\end{tabular}

Tabela 3 - Grelha de análise adotada para análise do conceito de 'Ambiente' (alunos/docentes)

Fonte: Elaboração própria com base em United Nations Educational, Scientific, and Cultural Organization. UNESCO (1978); Bodelón (1980); Ramón (1981); Yunén (1995); Programa das Nações Unidas para o Desenvolvimento - PNUD (1997).

Finalmente, as técnicas de investigação utilizadas na análise dos questionários, quanto às questões abertas, foram a análise de conteúdo e a estatística descritiva, quanto às questões fechadas, foram a estatística descritiva e a inferência estatística.

A utilização da escala bipolar de Likert permitiu avaliar as opiniões dos docentes e alunos, relacionadas com as 10 componentes da rede ACES. Aos alunos foram administradas 26 questões de opinião e aos docentes 10. Optou-se pela simplicidade que os quatro níveis (1nada; 2-pouco; 3-bastante; 4-muito) de resposta oferecem, eliminando-se a opção central. Este facto obrigou os respondentes a optarem apenas por respostas positivas ou negativas, o que é legítimo neste caso, dado tratar-se de uma matéria familiar aos mesmos e dado o seu nível educacional. Nesta análise foi efetuado o estudo de médias ponderadas.

Para editar, ordenar e tratar a informação foram utilizados o Statistical Package for Social Sciences - SPSS (versão 'SPSS for Windows 16') e o Microsoft Excel (versão 'Excel 12.0 for Office 2007'). 


\begin{tabular}{|c|c|c|}
\hline \multicolumn{3}{|c|}{ Desenvolvimento Sustentável } \\
\hline Dimensões & Categorias & Subcategorias \\
\hline \multirow{6}{*}{ - Social } & - Equidade & $\begin{array}{l}\text { - Pobreza } \\
\text { - Igualdade de género }\end{array}$ \\
\hline & - Saúde & $\begin{array}{l}\text { - Nutrição } \\
\text { - Cuidados de saúde } \\
\text { - Mortalidade } \\
\text { - Água potável } \\
\text { - Higiene } \\
\end{array}$ \\
\hline & - Educação & $\begin{array}{l}\text { - Nível de educação } \\
\text { - Alfabetização/literacia }\end{array}$ \\
\hline & - Habitação & - Condições de habitabilidade \\
\hline & - Segurança & - Crime \\
\hline & - População & - Migração \\
\hline \multirow{5}{*}{ - Ambiental } & - Atmosfera & $\begin{array}{l}\text { - Alterações climáticas } \\
\text { - Destruição da camada de ozono } \\
\text { - Qualidade do ar }\end{array}$ \\
\hline & - Terra & $\begin{array}{l}\text { - Agricultura } \\
\text { - Floresta } \\
\text { - Desertificação } \\
\text { - Urbanização }\end{array}$ \\
\hline & - Oceanos, mares e áreas costeiras & $\begin{array}{l}\text { - Zona costeira } \\
\text { - Pesca }\end{array}$ \\
\hline & - Água doce & $\begin{array}{l}\text { - Quantidade } \\
\text { - Qualidade } \\
\end{array}$ \\
\hline & - Biodiversidade & $\begin{array}{l}\text { - Ecossistemas } \\
\text { - Espécies } \\
\end{array}$ \\
\hline \multirow[b]{2}{*}{ - Económica } & - Estrutura económica & $\begin{array}{l}\text { - Performance } \\
\text { - Comércio } \\
\text { - Finanças } \\
\end{array}$ \\
\hline & - Padrão de produção e consumo & $\begin{array}{l}\text { - Consumo de recursos } \\
\text { - Uso da energia } \\
\text { - Gestão de resíduos } \\
\text { - Políticas de transporte }\end{array}$ \\
\hline \multirow[b]{2}{*}{ - Institucional } & - Quadro institucional & $\begin{array}{l}\text { - Estratégias de implementação do DS } \\
\text { - Cooperação internacional }\end{array}$ \\
\hline & - Capacidade institucional & $\begin{array}{l}\text { - Acesso à informação } \\
\text { - Infraestruturas de comunicação } \\
\text { - Ciência e tecnologia } \\
\text { - Preparação e resposta a desastres }\end{array}$ \\
\hline
\end{tabular}

Tabela 4 - Grelha de análise adotada para a análise do conceito de 'Desenvolvimento Sustentável' (alunos) Fonte: Indicadores de desenvolvimento sustentável aprovados pela Comissão de Desenvolvimento Sustentável (United Nations - UN, 2001).

\section{A ESCOLA SUPERIOR AGRÁRIA DO INSTITUTO POLITÉCNICO DE BRAGANÇA E A LICENCIATURA EM ENFERMAGEM VETERINÁRIA}

O Instituto Politécnico de Bragança - IPB é uma instituição de ensino superior público constituída por cinco escolas, a Escola Superior Agrária, a Escola Superior de Educação, a Escola Superior de Tecnologia e Gestão, a Escola Superior de Saúde e a Escola Superior de Comunicação, Administração e Turismo. Todas oferecem três graus de formação, designadamente: Cursos de Especialização Tecnológica (formação profissional com a duração de um ano); Cursos de Licenciatura (primeiro ciclo de Bolonha, com a duração de três anos); Cursos de Mestrado (segundo ciclo de Bolonha, com a duração de dois anos).

A partir do ano de 2007 que os cursos da ESAB foram reestruturados em conformidade com as premissas de Bolonha. A sua oferta educativa desenvolve-se na área das Ciências Agrárias 


\section{Egitania}

$s$ c i e $\Omega$ c i a

e Ambientais, com uma forte componente prática laboratorial e de campo, com domínios do saber e da formação, nas temáticas da agricultura, engenharia rural, engenharia alimentar, biotecnologia, ciência animal, ambiente, gestão dos recursos naturais, entre outras.

Em 2011 a ESAB dispunha de um corpo docente de 89 professores: 4 professores coordenadores, 66 professores adjuntos, 1 equiparado a professor adjunto, 7 equiparados a assistente e 11 equiparados a assistente em regime de tempo parcial (Relatório de Atividades do IPB - RAIPB-ESA, 2011). Nesse mesmo ano, 62 docentes possuíam o grau de doutor (a maioria dos quais acumula o grau de mestre), 65, possuíam o grau de mestre, e 11, preparavam o doutoramento (RAIPB-ESA, 2011). O corpo de pessoal não docente era constituído por 15 técnicos superiores, 9 assistentes técnicos e 22 assistentes operacionais, o que perfazia um total de 46 elementos (RAIPB-ESA, 2011).

A licenciatura em EV veio responder às exigências que a sociedade atual confere à saúde e bem-estar animal, tanto no âmbito dos animais de companhia, como dos animais de interesse zootécnico e cinegético. Para oferecer à região um serviço de qualidade, em analogia ao que acontece com os cuidados de saúde humana, tornou-se necessária a formação de técnicos qualificados em saúde animal para apoiar a prática clínica veterinária. Assim, pretendeu-se com este curso formar profissionais com capacidades técnicas e científicas em diversas atividades de apoio à Medicina Veterinária.

O programa de estudos confere aos alunos competências técnico-científicas e profissionais de diferentes áreas temáticas (Tabela 5).

\begin{tabular}{|l|c|c|}
\hline \multicolumn{1}{|c|}{ Área Científica } & Sigla & Créditos (ECTS) \\
\hline Biologia e Bioquímica & BIB & 36 \\
\hline Ciência Veterinária & CIV & 6 \\
\hline Ciências Físicas & CIF & 12 \\
\hline Ciências Sociais e Empresariais & CSE & 5 \\
\hline Informática & INF & 12 \\
\hline Produção Agrícola e Animal & PAA & 31 \\
\hline Tecnologia Veterinária & TEV & 180 \\
\hline Total & 7 & \\
\hline
\end{tabular}

Tabela 5 - Áreas científicas que integram o plano de estudos do curso de Enfermagem Veterinária

Fonte: Adaptado do Despacho $n^{\circ} 11368 / 2010$. Diário da República, II Série.

A licenciatura em Enfermagem Veterinária possui um total de 180 ECTS. O curso funciona em três anos (seis semestres curriculares com 810 horas por semestre) (Tabela 6). Para a realização do estágio profissional - Prática Veterinária - no último semestre do curso, a ESAB conta com diversas instituições parceiras. 


\begin{tabular}{|c|c|c|c|c|c|c|c|}
\hline \multirow[t]{2}{*}{ Ano } & \multirow[t]{2}{*}{ Sem } & \multirow[t]{2}{*}{ Unidade Curricular } & \multirow{2}{*}{$\begin{array}{c}\text { Área Cientí- } \\
\text { fica }\end{array}$} & \multirow[t]{2}{*}{ Tipo } & \multicolumn{2}{|c|}{$\begin{array}{c}\text { Tempo de Trabalho } \\
\text { (horas) }\end{array}$} & \multirow{2}{*}{$\begin{array}{c}\text { Créditos } \\
\text { ECTS }\end{array}$} \\
\hline & & & & & Total & Contacto & \\
\hline 1 & 1 & Anatomia & $\mathrm{CIV}$ & Sem. & 189 & 95 & 7.0 \\
\hline 1 & 1 & Etologia e Bem-estar Animal & CIV & Sem. & 135 & 65 & 5.0 \\
\hline 1 & 1 & Fisiologia I & $\overline{\mathrm{BIB}}$ & Sem. & 162 & 80 & 6.0 \\
\hline 1 & 1 & Microbiologia e Imunologia & $\overline{B I B}$ & Sem. & 162 & 80 & 6.0 \\
\hline 1 & 1 & Zootecnia Geral & $\overline{\mathrm{PAA}}$ & Sem. & 162 & 80 & 6.0 \\
\hline 1 & 2 & Biofísica & $\mathrm{ClF}$ & Sem. & 162 & 80 & 6.0 \\
\hline 1 & 2 & Bioquímica & $\overline{B I B}$ & Sem. & 162 & 80 & 6.0 \\
\hline 1 & 2 & Fisiologia II & $\mathrm{BIB}$ & Sem. & 162 & 80 & 6.0 \\
\hline 1 & 2 & Genética & $\overline{B I B}$ & Sem. & 162 & 80 & 6.0 \\
\hline 1 & 2 & Histologia e Anatomopatologia & CIV & Sem. & 162 & 80 & 6.0 \\
\hline 2 & 1 & Colheita de Amostras e Envio ao Laboratório & TEV & Sem. & 162 & 80 & 6.0 \\
\hline 2 & 1 & Ecologia e Biologia da Fauna Exótica e Silvestre & BIB & Sem. & 162 & 80 & 6.0 \\
\hline 2 & 1 & Introdução à Farmacologia e Anestesiologia & CIV & Sem. & 162 & 80 & 6.0 \\
\hline 2 & 1 & Nutrição Animal & $\overline{P A A}$ & Sem. & 162 & 80 & 6.0 \\
\hline 2 & 1 & Reprodução e Obstetrícia & CIV & Sem. & 162 & 80 & 6.0 \\
\hline 2 & 2 & Bioquímica e Análises Clínicas & TEV & Sem. & 162 & 80 & 6.0 \\
\hline 2 & 2 & $\begin{array}{l}\text { Doenças Infetocontagiosas e Parasitárias e Práticas de } \\
\text { Laboratório }\end{array}$ & CIV & Sem. & 162 & 90 & 6.0 \\
\hline 2 & 2 & Enfermagem Veterinária & CIV & Sem. & 189 & 95 & 7.0 \\
\hline 2 & 2 & Sistemas de Informação e de Apoio à Decisão & INF & Sem. & 135 & 65 & 5.0 \\
\hline 2 & 2 & Virologia e Cultura de Células Animais & TEV & Sem. & 162 & 80 & 6.0 \\
\hline 3 & 1 & Etica e Legislação & $\overline{C S E}$ & Sem. & 162 & 80 & 6.0 \\
\hline 3 & 1 & Métodos Complementares de Diagnóstico & TEV & Sem. & 189 & 95 & 7.0 \\
\hline 3 & 1 & Morfologia e Estética Animal & CIV & Sem. & 135 & 65 & 5.0 \\
\hline 3 & 1 & Organização e Gestão da Empresa & CSE & Sem. & 162 & 80 & 6.0 \\
\hline 3 & 1 & Saúde Pública Veterinária & TEV & Sem. & 162 & 80 & 6.0 \\
\hline 3 & 2 & Prática Veterinária & CIV & Sem. & 810 & 0 & 30.0 \\
\hline
\end{tabular}

Tabela 6 - Plano de estudos do curso de Enfermagem Veterinária

Fonte: Adaptado do Despacho n. ${ }^{\circ} 11368 / 2010$. Diário da República, II Série.

O grau de 'Licenciado em Enfermagem Veterinária' é conferido aos alunos que demonstrem ter adquirido competências científicas sólidas nos vários domínios do currículo académico. 


\section{Egitania}

$s$ c i e $\Omega$ c i a

\section{APRESENTAÇÃO DOS RESULTADOS}

Iremos observar neste ponto o perfil da ESAB, dos alunos e dos docentes, a literacia ambiental dos alunos e dos docentes e a sustentabilidade curricular da licenciatura em EV, com base na informação fornecida pelos alunos, pelos docentes e pelo plano de estudos do curso.

\subsection{O PERFIL DA ESAB}

A ESAB é uma instituição 'amiga do ambiente' quanto à gestão de energia, água e resíduos. Implementou o Projeto EcoESAB (Sistema de Gestão Ambiental - Norma ISO 14001); o Projeto Campus Vivo de Energias Renováveis - VERCampus; possui órgãos internos de gestão que elaboram periodicamente relatórios ambientais (conhecimento à comunidade académica das atividades de poupança e gestão de recursos implementadas nas instalações); e, proporciona à comunidade académica e à população da região a prática de agricultura biológica no campus.

A Escola organiza eventos na área das ciências agroambientais e possui diversos projetos de investigação nas áreas da agricultura sustentável e do ambiente: ecossistemas, conservação da biodiversidade, valorização de agroecossistemas, ordenamento do território e sistemas sociais.

A instituição possui uma oferta formativa de cariz agrário, cujos planos curriculares envolvem matérias relacionadas com diversas componentes do ambiente. Oferece unidades curriculares de livre opção e disciplinas extracurriculares não incluídas nos planos de estudo, assim como espaços de diálogo para o debate de questões ambientais, científicas e económicas, mas é reduzida a oferta de eventos relacionados com a educação, a cultura, a sociedade e as políticas governamentais.

A inclusão social dos alunos está presente na instituição, que acolhe alunos estrangeiros em quase todas as áreas de formação. É positivo o atendimento prestado aos alunos pelos diversos serviços da Escola e existe uma relação aberta e cordial recíproca entre os alunos e a Academia.

No entanto, embora se tenha observado que o envolvimento das IES para com a sustentabilidade se tem fundamentado nos acordos, valores e princípios emanados por diplomas produzidos em ações de caráter internacional (ESAB incluída) e que foram assumidos compromissos no âmbito do Programa COPERNICUS e Declaração de Bolonha, não foi implementada pela Escola uma estratégia de Educação Ambiental para o Desenvolvimento Sustentável - EADS subjacente a esses acordos, que envolva toda a comunidade e as instituições parceiras.

\subsection{O PERFIL DOS ALUNOS E DOS DOCENTES}

Quanto ao perfil dos alunos, verificou-se o predomínio de estudantes do género feminino (21) sobre o género masculino (7), com uma faixa etária compreendida entre os 21 e 27 anos.

Três alunos eram membros de associações ambientais, seis eram membros do Núcleo de Enfermagem Veterinária, um participou em atividades ambientais da EcoESAB, oito participaram 


\section{Egitania}

$s$ c i e $\Omega$ c i a

em campanhas de adoção de animais (Associação Amicus Canis, AMICA), vinte e três participaram em atividades cívicas, de solidariedade social e de angariação de alimentos para familias carenciadas e vinte e cinco realizaram o estágio profissional em hospitais ou clínicas veterinárias no tratamento de animais de companhia ou animais de grande porte.

Relativamente ao perfil dos docentes, cinco eram do género feminino e onze do género masculino, com idades compreendidas entre 31 e 56 anos. Sete docentes possuíam o grau de doutor, seis o grau de mestre, um a pós-graduação e dois a licenciatura. As áreas de formação do corpo docente eram a Medicina Veterinária, Ciência Animal, Ciências da Terra e da Vida, Ciências Sociais e Empresariais e Informática. Dois docentes eram membros de associações ambientais. O sistema de gestão ambiental, EcoESAB, era conhecido por seis docentes e o processo de ACES por quatro. Nenhum docente possuía formação sólida em Educação Ambiental, referindo seis, que a sua formação de base 'não os preparou para integrar a temática ambiental nas disciplinas que lecionam', e catorze, que o que mais os preparou para lecionar as disciplinas de acordo com alguns princípios de Educação Ambiental foi a 'formação autodidata', a 'formação académica' e a 'informação veiculada pelos meios de comunicação'. Todos os docentes concordaram com a inclusão da sustentabilidade curricular nos cursos da ESAB. Dez docentes consideraram que 'o melhor procedimento para a introdução da temática ambiental no ensino superior seria a sua inclusão de modo transversal nos programas curriculares'.

\subsection{A LITERACIA AMBIENTAL DOS ALUNOS E DOS DOCENTES}

Um indivíduo dotado de literacia ambiental deverá possuir a capacidade de análise, interpretação, síntese e avaliação da informação disponível para tomar decisões responsáveis e a motivação necessária para desenvolver atividades, pessoais e coletivas, relativas ao Ambiente (Fernandes et al., 2007). Foi neste contexto que se pretendeu observar os conhecimentos dos docentes e dos alunos sobre os conceitos que a seguir se apresentam.

\subsubsection{Conceito de 'Ambiente'}

Quanto ao conceito de 'Ambiente' na ótica dos alunos, treze, associaram-no unicamente à sua componente 'Natural', relegando as componentes 'Social' e 'Construída'. Quatro alunos relacionaram os 'problemas ambientais' com a totalidade das opções ${ }^{4}$ apresentadas no questionário. Na tentativa de definir 'Ambiente', as respostas dos alunos situaram-se no contexto das 'consequências' pelos danos que the são causados.

A maioria dos alunos referiu o 'aquecimento global' (28 ocorrências), a 'desflorestação' (28 ocorrências) e a 'escassez de água' (24 ocorrências) como os maiores danos ambientais, e desvalorizou a 'injustiça, pobreza, fome' (9 ocorrências) e a 'compra de produtos produzidos por crianças' (5 ocorrências).

Relativamente ao conceito de 'Ambiente' na ótica dos docentes foram observadas duas posições:

4 Extinção do lince-ibérico; Guerras; Ruído de trânsito; Produção e consumo excessivos; Desflorestação; Escassez de água; Aquecimento global; Injustiça, pobreza e fome; Compra de produtos produzidos por crianças; Aumento da população. 
- visão antropocêntrica (quinze docentes referiram-se ao Ambiente como 'natureza/recurso' e 'um lugar para viver', colocando o 'ser humano no centro');

- visão ecocêntrica (um docente referiu-se às 'três componentes do Ambiente', colocando a 'vida no centro').

Apenas quatro docentes selecionaram a totalidade das opções ${ }^{5}$ relacionadas com os 'problemas ambientais'. O 'aquecimento global' (15 ocorrências), a 'escassez de água' (13 ocorrências), a 'contaminação' (13 ocorrências) e a 'produção e consumo excessivos' (13 ocorrências) foram designados como os problemas mais danosos para o Ambiente.

\subsubsection{O Conceito de 'Desenvolvimento Sustentável' na Ótica dos}

\section{Alunos}

Cerca de 1/3 dos alunos integrou no conceito de 'Desenvolvimento Sustentável' a 'sociedade em equilibrio com o Ambiente' e referiram-se à 'preservação dos recursos naturais no presente e no futuro'.

Segundo a grelha de análise adotada para observar o conceito de DS, foram evidenciadas pelos alunos três das suas quatro dimensões: a dimensão social, ambiental e económica. Não foi referida a dimensão institucional do DS, intimamente relacionada com as formas de governação (instituições públicas e privadas, sistema legislativo e sindicatos).

\subsubsection{O Conceito de 'Educação Ambiental para o Desenvolvimento Sustentável' na Ótica dos Docentes}

Onze docentes referiram-se à 'educação para a defesa do ambiente para o presente e para o futuro, pois dele depende a vida humana', e cinco, acrescentaram à ideia anterior alguns aspetos interessantes, com uma visão mais ecocêntrica da EADS, como:

- a aquisição de conhecimentos e competências para a sustentabilidade;

- o conhecimento das relações sociedade-ambiente;

- a consciência cívica dos alunos;

- o desenvolvimento de um comportamento responsável;

- proporcionar conhecimento para a aquisição de aptidões para lidar com a vida.

\footnotetext{
5 Importação de óleo de palma da Indonésia; Espaços protegidos; Comunicação; Legislação; Compra de produtos produzidos por crianças; Contaminação; Migrações; Agro-combustíveis; Injustiça, pobreza e fome; Movimentos reivindicativos; Politica; Religião; Guerras; Crise financeira na União Europeia; Campos de golfe; Ética; Escassez de água; Transporte e mobilidade; Turismo; Fontes de energia; Aumento da população; Tecnociência; Exclusão social; Dívida externa; Produção e consumo excessivos; Ruído de trânsito; Educação; Resíduos; Floresta; Aquecimento global; Urbanismo; Biodiversidade; Crise energética; Extinção do lobo-ibérico; Indústria.
} 


\section{Egitania}

$s$ c i e $\Omega$ c i a

\subsection{A SUSTENTABILIDADE CURRICULAR DA LICENCIATURA EM ENFERMAGEM VETERINÁRIA}

Observaremos de seguida os resultados da sustentabilidade curricular da licenciatura em Enfermagem Veterinária por característica da rede ACES (questionários aos alunos e docentes) e por disciplina (plano de estudos). Posteriormente serão confrontados os resultados das diversas fontes de informação utilizadas, de modo a estimar a sustentabilidade curricular global da licenciatura (Figura 3).

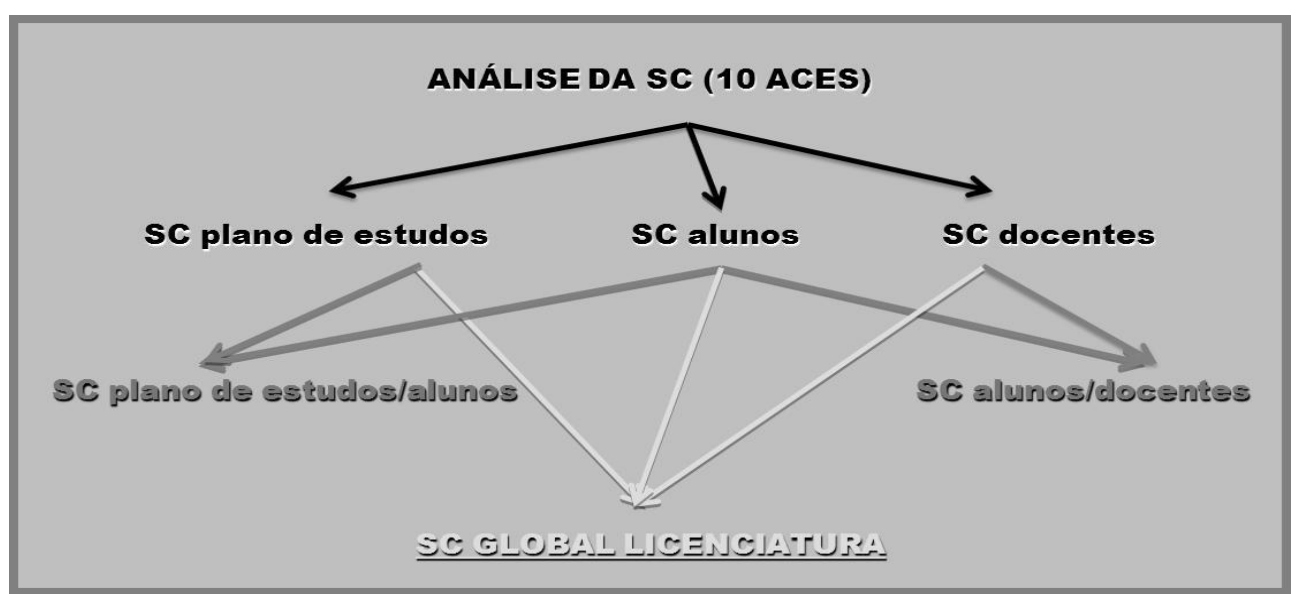

Figura 3 - Análise da sustentabilidade curricular segundo as 10 características da rede ACES

\subsubsection{A Sustentabilidade Curricular por Característica de Acordo com os Alunos e os Docentes}

Como já referido, foi efetuado o estudo das médias ponderadas com quatro níveis de resposta, segundo a escala de Likert (Figura 4).

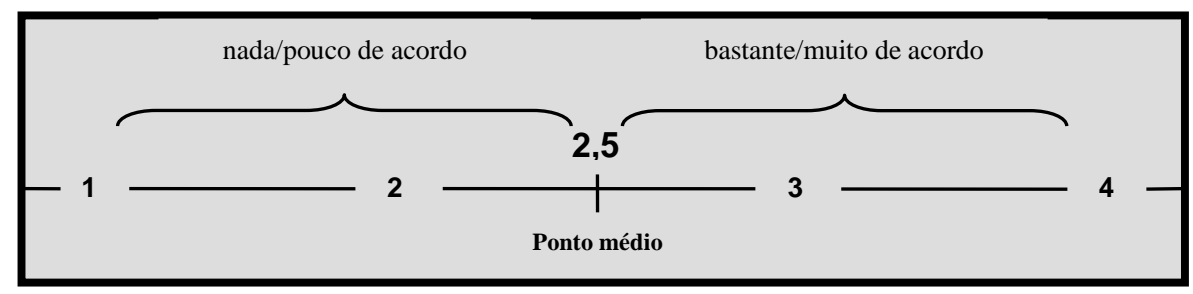

Figura 4: A escala de Likert segundo quatro níveis de resposta.

Na Tabela 7 exibem-se as médias ponderadas das questões apresentadas aos alunos (Anexo) e as médias aritméticas dos indicadores e características da rede ACES.

Para além da fraca permeabilidade no curso (1,9 - característica II), observou-se na Tabela 7 que não é muito promovida, por parte dos docentes, a 'organização de eventos com parceiros externos' (2,5 - característica III) e que os alunos não 'entregam os trabalhos em papel frente e verso ou reciclado' e não 'separam as embalagens no bar da ESAB e o procuram manter limpo' (respetivamente 2,2 e 2,3 - característica VII).

A Tabela 8 apresenta as médias ponderadas das questões (Anexo) e as médias aritméticas dos indicadores e características da rede ACES, no âmbito das respostas dos docentes. 


\section{Egitania}

$s$ c i e $\Omega$ c i a

Para além de confirmada pelos docentes a fraca permeabilidade no curso (2,0 - característica II), observam-se, na característica III, valores relativamente baixos no que respeita a:

- 'inclusão de problemáticas de outras áreas de conhecimento' nas aulas $(2,5)$;

- 'organização de eventos com parceiros externos' (2,6);

- 'participação em projetos de diferentes áreas de conhecimento' $(2,4)$.

Estes valores vêm reforçar que, no contexto das dez características, a maior debilidade da licenciatura assenta na carência de diálogo entre os docentes que lecionam disciplinas relacionadas entre si, e entre os docentes e os parceiros externos, tanto ao nível da organização de eventos como ao nível na participação em projetos de áreas de conhecimento diferentes das suas.

Outras fragilidades do curso estão patentes na:

- característica IV, 'participação em reuniões de avaliação do curso' $(2,0)$;

\begin{tabular}{|c|c|c|c|c|}
\hline \multirow{2}{*}{ Características } & \multirow{2}{*}{ Questões (alunos) } & \multicolumn{3}{|c|}{ Valores Médios } \\
\hline & & Quest. & Indic. & Caract. \\
\hline \multicolumn{5}{|c|}{ I. Complexidade: formas de olhar o mundo } \\
\hline Recontexłualização & Análise histórica e epistemológica das disciplinas & 3,4 & 3,4 & \multirow{6}{*}{3,2} \\
\hline \multirow{4}{*}{$\begin{array}{l}\text { Pensamento crítico e } \\
\text { imaginação }\end{array}$} & Estímulo ao debate nas aulas & 3,0 & \multirow{4}{*}{3,2} & \\
\hline & Estímulo à imaginação e criatividade & 3,2 & & \\
\hline & Visão complexa do mundo & 3,0 & & \\
\hline & Conhecimento tecnocientífico dos docentes & 3,4 & & \\
\hline Multicausalidade & Visão dinâmica e multicausal dos fenómenos & 3,3 & 3,3 & \\
\hline \multicolumn{5}{|c|}{ II. Ordem disciplinar: flexibilidade e permeabilidade } \\
\hline Flexibilidade & - & - & - & \multirow{3}{*}{1,9} \\
\hline \multirow[b]{2}{*}{ Permeabilidade } & Docentes de diferentes áreas de conhecimento & 1,9 & \multirow[b]{2}{*}{1,9} & \\
\hline & Participação de profissionais externos nas aulas & 1,8 & & \\
\hline \multicolumn{5}{|c|}{ III. Contextualização: abordagem das temáticas em diferentes escalas de tempo e espaço } \\
\hline \multirow{2}{*}{$\begin{array}{l}\text { Contexto económico } \\
\text { tecnológico, social... }\end{array}$} & Problemáticas de outras áreas de conhecimento & 3,1 & \multirow{2}{*}{2,8} & \multirow{2}{*}{2,8} \\
\hline & Organização de eventos com parceiros externos & 2,5 & & \\
\hline \multicolumn{5}{|c|}{ IV. Considerar o sujeito na construção do conhecimento } \\
\hline \multirow{3}{*}{ Estrutura do currículo } & Concordância com a organização do plano curricular & 3,4 & \multirow{2}{*}{3,6} & \multirow{5}{*}{3,6} \\
\hline & \begin{tabular}{|l} 
Importância e relação das disciplinas para a formação \\
\end{tabular} & 3,8 & & \\
\hline & & 34 & 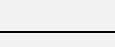 & \\
\hline \multirow{2}{*}{$\begin{array}{l}\text { Funcionamento } \\
\text { atividade letiva }\end{array}$} & Concordância com as metodologias adotadas & 3,4 & \multirow[t]{2}{*}{3,5} & \\
\hline & Ter em conta a opinião dos alunos & 3,6 & & \\
\hline \multicolumn{5}{|c|}{ V. Considerar os aspetos cognitivos, afetivos e de ação das pessoas } \\
\hline \multirow{2}{*}{ Inclusão social do aluno } & Reforço das habilidades sociais e entreajuda & 3,4 & \multirow{2}{*}{3,4} & \multirow{4}{*}{3,5} \\
\hline & Fomento da autonomia e autoestima & 3,5 & & \\
\hline Multiculturalidade & - & - & - & \\
\hline Compet. básicas & - & - & - & \\
\hline
\end{tabular}




\section{Egitania}

s c i e $\Omega$ c i a

\begin{tabular}{|c|c|c|c|c|}
\hline \multicolumn{5}{|c|}{ VI. Coerência e reconstrução entre teoria e prática } \\
\hline Coer. institucional & - & - & - & \multirow{3}{*}{3,7} \\
\hline \multirow{2}{*}{ Coerência docente } & Discurso e postura coerentes & 3,7 & \multirow{2}{*}{3,7} & \\
\hline & \begin{tabular}{|c|} 
Coerência e articulação entre teoria e prática \\
\end{tabular} & 3,6 & & \\
\hline \multicolumn{5}{|c|}{ VII. Orientação prospetiva de cenários alternativos: respeito pelas gerações futuras } \\
\hline \multirow{11}{*}{ Sustentabilidade } & O curso forma profissionais preocupados com a sustentabilidade ambiental & 3,3 & \multirow{11}{*}{3,1} & \multirow{12}{*}{2,9} \\
\hline & $\begin{array}{l}\text { O futuro profissional dos alunos poderá contribuir para a melhoria da } \\
\text { qualidade ambiental e da qualidade de vida da sociedade }\end{array}$ & 3,0 & & \\
\hline & Entrega dos trabalhos em formato eletrónico & 2,9 & & \\
\hline & \begin{tabular}{|l|} 
Entrega dos trabalhos em papel frente e verso ou reciclado \\
\end{tabular} & 2,2 & & \\
\hline & Solicitação de documentos fotocopiados frente e verso & 3,2 & & \\
\hline & \begin{tabular}{|l} 
Reciclagem de diferentes tipos de materiais \\
\end{tabular} & 2,9 & & \\
\hline & \begin{tabular}{|l|} 
Valorização da presença de plantas nos corredores e no campus \\
\end{tabular} & 3,8 & & \\
\hline & \begin{tabular}{|l|} 
Apagam-se as luzes quando há luz natural suficiente \\
\end{tabular} & 3,7 & & \\
\hline & Fecha-se a torneira da água quando não é necessária & 3,7 & & \\
\hline & \begin{tabular}{|l} 
Separam-se as embalagens no bar da ESAB e mantém-se o local limpo \\
\end{tabular} & 2,3 & & \\
\hline & Participa-se ativamente na proteção e melhoria do ambiente & 2,6 & & \\
\hline Interdisciplinaridade & $\begin{array}{l}\text { Reforça-se o trabalho interdisciplinar para solucionar desafios atuais e } \\
\text { futuros }\end{array}$ & 2,8 & 2,8 & \\
\hline \multicolumn{5}{|l|}{ VIII. Adequação metodológica } \\
\hline \multirow{3}{*}{$\begin{array}{l}\text { Metodologias } \\
\text { participativas }\end{array}$} & As metodologias são adequadas aos conteúdos curriculares & 3,6 & \multirow{3}{*}{3,3} & \multirow{4}{*}{3,3} \\
\hline & Utilizam-se metodologias de reflexão/participação em problemas reais & 3,2 & & \\
\hline & $\begin{array}{l}\text { Realizam-se trabalhos de grupo, estudos de caso, trabalhos de campo e } \\
\text { visitas de estudo }\end{array}$ & 3,1 & & \\
\hline Multipl. perspetivas & - & - & - & \\
\hline \multicolumn{5}{|c|}{ IX. Gerar espaços de reflexẫo e participação democrática } \\
\hline Democracia participativa & Participa-se em debates, trabalhos de grupo e outras atividades nas aulas & 3,2 & 3,2 & 3,2 \\
\hline \multicolumn{5}{|c|}{ X. Compromisso com a transformação das relações sociedade-natureza } \\
\hline \multirow{2}{*}{$\begin{array}{l}\text { Compromisso político, } \\
\text { económico e de ação }\end{array}$} & $\begin{array}{l}\text { Promovem-se valores que motivem os alunos a participar na melhoria do } \\
\text { ambiente }\end{array}$ & 2,9 & \multirow{2}{*}{2,9} & \multirow{2}{*}{2,9} \\
\hline & $\begin{array}{l}\text { O curso prepara os alunos para contribuírem para a melhoria da qualidade } \\
\text { socioambiental }\end{array}$ & 2,9 & & \\
\hline
\end{tabular}

Tabela 7 - Sustentabilidade curricular segundo os alunos da licenciatura em Enfermagem Veterinária estruturada com base nas dez características da rede ACES

Nota: As áreas a branco (-) indicam que a informação recolhida não teve origem nos inquéritos aos alunos.

- característica VII, 'considera-se a possibilidade de realizar um plano de sustentabilidade curricular para as disciplinas' $(2,3)$;

- característica VIII, 'realizam-se trabalhos de campo e visitas de estudo' $(2,4)$;

\begin{tabular}{|l|l|c|c|c|}
\hline \multirow{2}{*}{ Características } & \multicolumn{1}{|c|}{ Questões (docentes) } & \multicolumn{3}{c|}{ Valores Médios } \\
\cline { 3 - 5 } & & Quest. & Indic. & Caract. \\
\hline I. Complexidade: formas de olhar o mundo & \multicolumn{2}{|c|}{2,8} & \multirow{2}{*}{2,9} \\
\hline \multirow{2}{*}{ Recontextualização } & Análise histórica e epistemológica das disciplinas & 2,8 & & \\
\cline { 2 - 4 } & Contextualização das disciplinas no espaço e no tempo & & \\
\hline
\end{tabular}




\section{Egitania}

$s$ c i e $\Omega$ c i a

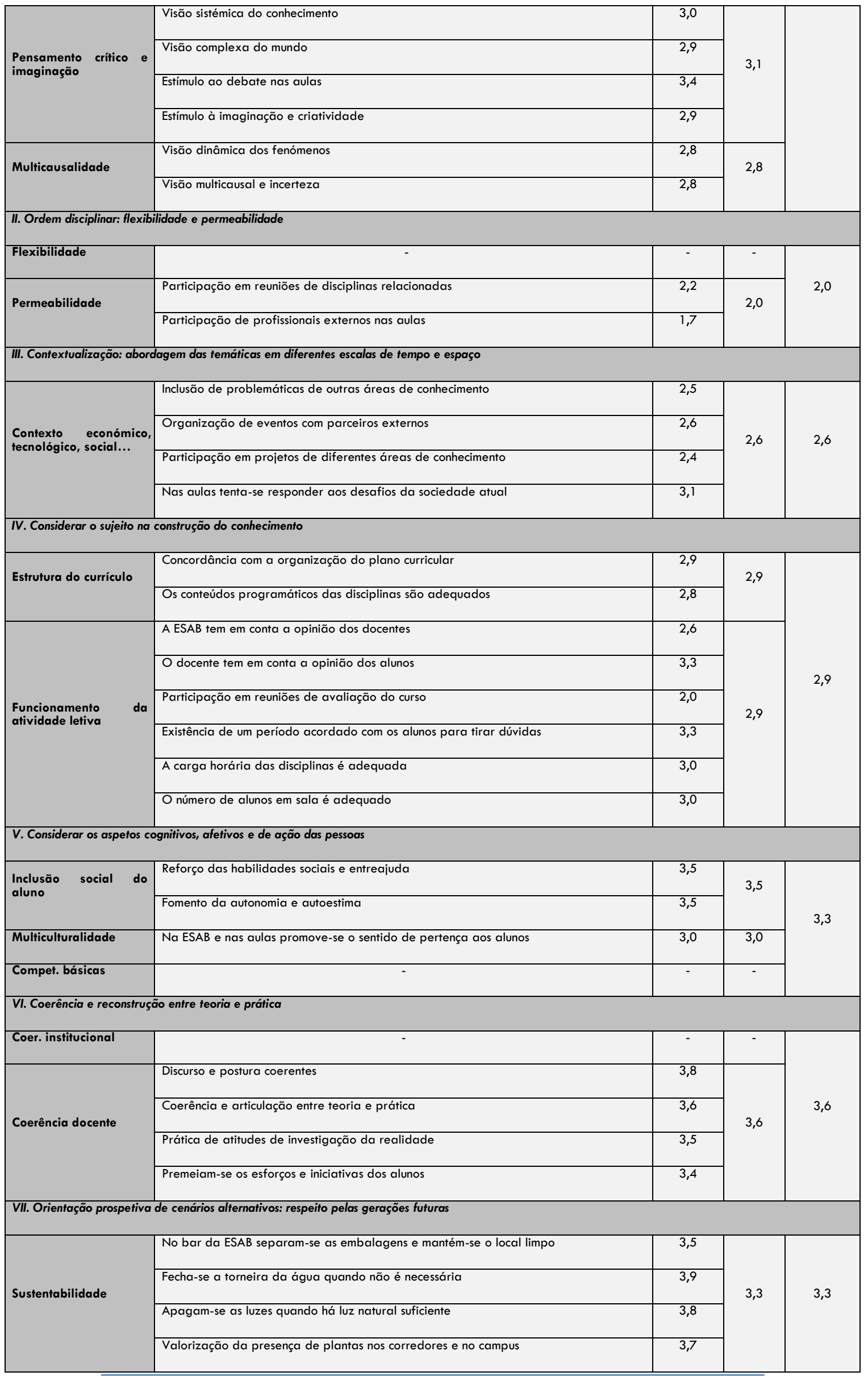




\section{Egitania}

s c i e $\Omega$ c i a

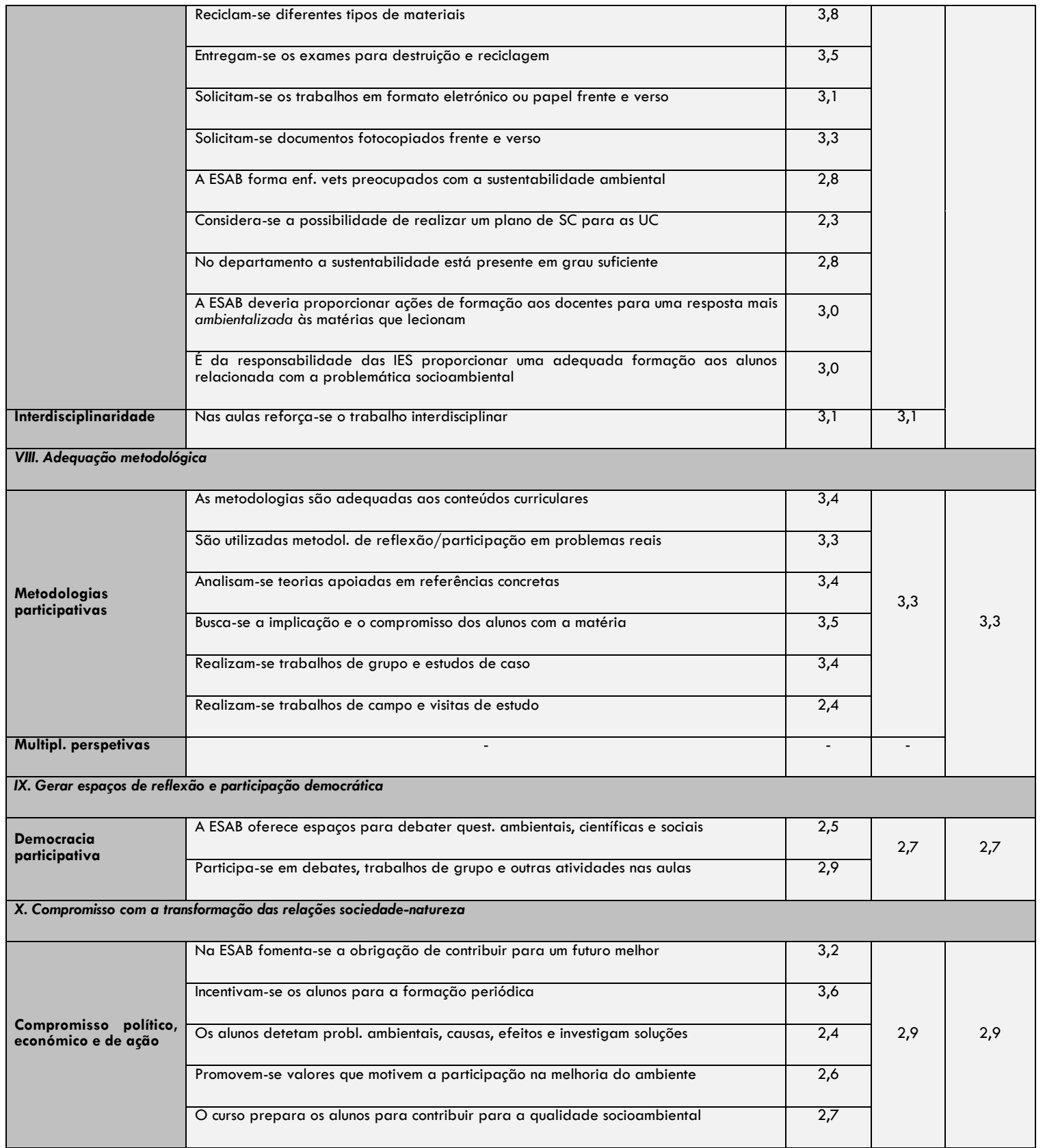

Tabela 8 - Sustentabilidade curricular segundo os docentes da licenciatura em Enfermagem

Veterinária estruturada com base nas dez características da rede ACES

Nota: As áreas a branco (-) indicam que a informação recolhida teve origem em questões abertas.

- característica X, 'ajudam-se os alunos a detetar problemas ambientais, suas causas e efeitos e investigar possíveis soluções' $(2,4)$.

A fraca participação dos docentes nas reuniões de avaliação do curso deve-se à discordância manifestada para com as normas subjacentes ao processo de avaliação.

Apesar de se realizarem bastantes 'trabalhos de grupo e estudos de caso' (3,4), não são tão frequentes os 'trabalhos de campo e as visitas de estudo' $(2,4)$, o que, de facto, seria expectável, já que os primeiros são executados na sala de aula. 


\section{Egitania}

$s$ c i e $\Omega$ c i a

Embora os dados recolhidos informem que existe sustentabilidade curricular no curso de Enfermagem Veterinária, os docentes ainda não estão sensibilizados $(62,5 \%)$ para realizar um plano de sustentabilidade curricular para as suas disciplinas. Há docentes que consideram que:

- as suas unidades curriculares 'estão ambientalizadas';

- possuem 'carência de formação em ambiente';

- o 'ambiente não se enquadra nas disciplinas que lecionam';

- as 'áreas científicas que abordam nas aulas se regem por leis universais', afirmando, portanto, que não se relacionam com o Ambiente;

- apenas introduzirão critérios de sustentabilidade curricular se a legislação o exigir.

Nesta conformidade, é natural que uma parte dos docentes não apoie os alunos na 'deteção de problemas ambientais, suas causas, efeitos e na investigação de possíveis soluções', o que fomentaria um maior compromisso sociedade-natureza.

Das tabelas anteriores pode inferir-se a média por característica em ambos os grupos de análise, que se apresenta na Tabela 9.

\begin{tabular}{|l|c|c|c|c|}
\hline \multirow{2}{*}{ Características } & \multicolumn{3}{|c|}{ Valor Médio por Característica } \\
\cline { 2 - 5 } & alunos & docentes & (alunos/docentes) & diferença \\
\hline $\begin{array}{l}\text { I. Complexidade: formas de olhar o } \\
\text { mundo }\end{array}$ & 3,21 & 2,92 & 3,06 & 0,29 \\
\hline $\begin{array}{l}\text { II. Ordem disciplinar: flexibilidade e } \\
\text { permeabilidade }\end{array}$ & 1,93 & 1,96 & 1,94 & 0,03 \\
\hline $\begin{array}{l}\text { III. Contextualização: abordagem das } \\
\text { temáticas em diferentes escalas de } \\
\text { tempo e espaço }\end{array}$ & 2,80 & 2,64 & 2,72 & 0,16 \\
$\begin{array}{l}\text { IV. Considerar o sujeito na construção } \\
\text { do conhecimento }\end{array}$ & 3,55 & 2,87 & 3,21 & 0,68 \\
\hline $\begin{array}{l}\text { V. Considerar os aspetos cognitivos, } \\
\text { afetivos e de ação das pessoas }\end{array}$ & 3,45 & 3,31 & 3,38 & 0,14 \\
\hline $\begin{array}{l}\text { VI. Coerência e reconstrução entre } \\
\text { teoria e prática }\end{array}$ & 3,69 & 3,58 & 3,63 & 0,11 \\
\hline $\begin{array}{l}\text { VIII. Orientação prospetiva de cenários } \\
\text { alternativos: respeito pelas gerações } \\
\text { futuras }\end{array}$ & 2,90 & 3,26 & 3,08 & 0,36 \\
\hline VIII. Adequação metodológica & 3,30 & 3,25 & 3,27 & 0,05 \\
\hline $\begin{array}{l}\text { IX. Gerar espaços de reflexão e } \\
\text { participação democrática }\end{array}$ & 3,20 & 2,70 & 2,95 & 0,50 \\
\hline $\begin{array}{l}\text { X. Compromisso com a transformação } \\
\text { das relações sociedade/natureza }\end{array}$ & 2,90 & 2,88 & 2,89 & 0,02 \\
\hline TOTAlS & 3,09 & 2,94 & 3,01 & 0,15 \\
\hline
\end{tabular}

Tabela 9 - Valor médio por característica alunos/docentes

De notar que as diferenças entre os resultados dos dois grupos são quase impercetíveis, embora seja visível uma maior divergência no âmbito das características IV $(0,68)$ e IX $(0,5)$. De qualquer modo, a tabela exibe claramente avaliações análogas para a sustentabilidade curricular do curso, embora os alunos efetuem uma avaliação mais favorável.

De salientar ainda que ambos os grupos apontaram para uma maior sustentabilidade curricular na característica VI $(3,69$ e 3,58) e menor na característica II $(1,93$ e 1,96) (abaixo do ponto médio). 


\section{Egitania}

$s$ c i e $\Omega$ c i a

Globalmente, de acordo com os alunos a sustentabilidade curricular do curso é 3,09 e de acordo com os docentes 2,94.

\subsubsection{A Sustentabilidade Curricular por Disciplina de Acordo com o Plano de Estudos e com os Alunos}

A Tabela 10 sintetiza os resultados da avaliação das unidades curriculares no âmbito dos planos de estudo e programas das disciplinas (segunda coluna: frequência das expressões e palavraschave referentes a um currículo sustentável) e da informação primária (restantes colunas: valores médios das cotações das respostas dos alunos).

Da observação da Tabela, no contexto da informação secundária, as unidades curriculares de 'Ecologia e Biologia da Fauna Exótica e Silvestre', 'Reprodução e Obstetrícia', 'Doenças Infetocontagiosas e Parasitárias e Práticas de Laboratório', 'Organização e Gestão da Empresa', 'Zootecnia Geral' e 'Saúde Pública Veterinária' foram as que mais se aproximaram de um currículo sustentável ( $\geq 3$ ) e as de 'Bioquímica', 'Fisiologia ll', 'Anatomia', 'Etologia e Bem-estar Animal', 'Histologia e Anatomopatologia', 'Sistemas de Informação e de Apoio à Decisão', 'Colheita de Amostras e Envio ao Laboratório' e 'Métodos Complementares de Diagnóstico', onde a sustentabilidade curricular esteve mais ausente ( $\leq 2)$. Nesta avaliação, doze unidades curriculares foram cotadas com valores inferiores a 2,5.

Também aqui, a avaliação efetuada pelos alunos é mais favorável, quando comparada com a informação secundária, exceto no que se refere à sustentabilidade curricular das disciplinas de 'Ecologia e Biologia da Fauna Exótica e Silvestre', 'Doenças Infetocontagiosas e Parasitárias e Práticas de Laboratório', 'Biofísica' e 'Zootecnia Geral'.

Como as fontes de informação secundária apenas nos advertiram sobre os indícios de sustentabilidade curricular no curso, foram complementadas com os questionários, de forma a garantir um conhecimento mais rico e rigoroso.

De harmonia com o exposto, os resultados apresentados na Tabela 10 evidenciam algumas diferenças entre a sustentabilidade curricular segundo os planos de estudo/programas das disciplinas e as aulas propriamente ditas. Este facto aponta para um 'currículo oculto', apenas visível na prática letiva em ação.

Assim, a sustentabilidade curricular com base nos documentos da instituição é de 2,5 (tangente ao valor médio) e com base na informação prestada pelos alunos é de 3,1 (acima do valor médio), ou seja, separa-as uma diferença de 0,6.

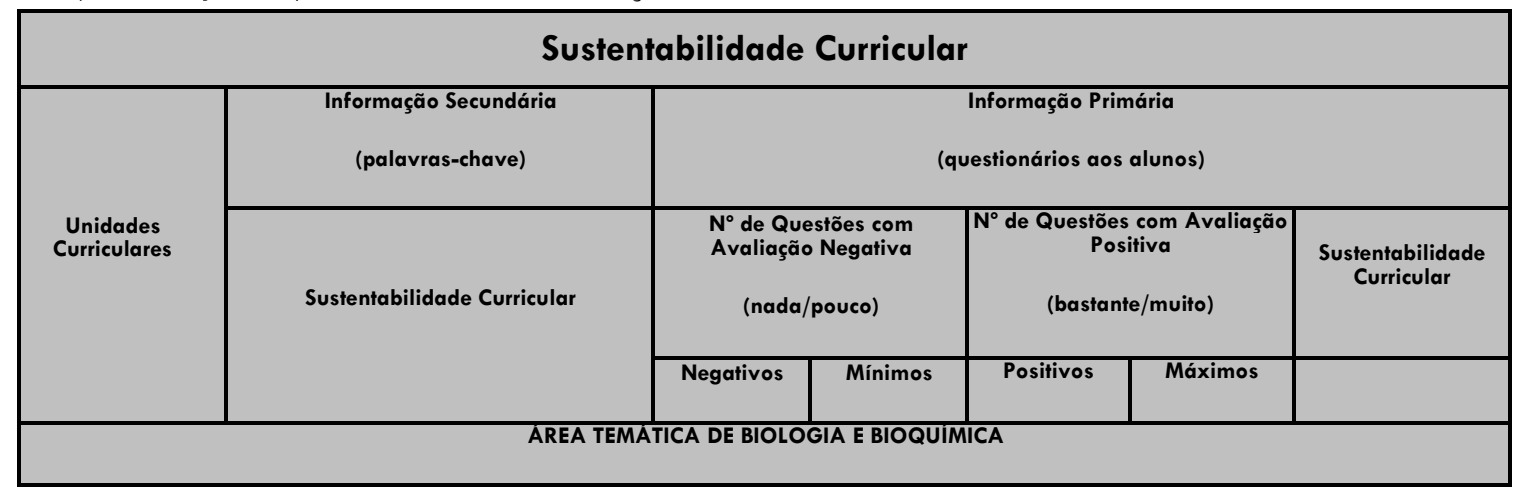


$s$ c i e $\Omega$ c i a

\begin{tabular}{|c|c|c|c|c|c|c|}
\hline FIS I & 2,6 & 5 & 2 & 19 & & 2,8 \\
\hline MI & 2,2 & 3 & - & 23 & & 3,1 \\
\hline BQ & 1,8 & 3 & - & 23 & & 2,9 \\
\hline FIS II & 1,8 & 5 & - & 21 & & 2,9 \\
\hline GENET & 2,7 & 2 & - & 24 & & 3,2 \\
\hline EBFES & 3,8 & 2 & - & 22 & 2 & 3,3 \\
\hline$S C B I B$ & 2,5 & & & & & 3,0 \\
\hline \multicolumn{7}{|c|}{ ÁREA TEMÁTICA DE CIËNCIAS VETERINARIAS } \\
\hline ANAT & 1,8 & 2 & - & 22 & 2 & $\mathbf{3 , 2}$ \\
\hline EBEA & 1,9 & 3 & - & 23 & & 3,2 \\
\hline HAP & 1,9 & 2 & - & 22 & 2 & $\overline{3,2}$ \\
\hline IFA & 2,1 & 2 & - & 22 & 2 & 3,3 \\
\hline RO & 3,2 & 1 & & 23 & 2 & 3,3 \\
\hline DICPPL & 3,8 & - & - & 23 & 3 & 3,4 \\
\hline EV & 2,6 & 2 & - & 24 & & 3,2 \\
\hline MEA & 2,7 & - & - & 26 & & 3,3 \\
\hline SC CIV & 2,5 & & & & & 3,3 \\
\hline \multicolumn{7}{|c|}{ AREA TEMATICA DE CIENCIAS FISICAS } \\
\hline BF & 2,6 & 2 & 10 & 14 & & 2,5 \\
\hline SC CIF & 2,6 & & & & & 2,5 \\
\hline \multicolumn{7}{|c|}{ AREA TEMÁTICA DE CIËNCIAS SOCIAIS E EMPRESARIAIS } \\
\hline EL & 2,9 & 2 & 1 & 10 & 13 & 3,4 \\
\hline OGE & 3,0 & 2 & - & 17 & 7 & 3,3 \\
\hline SC CSE & 3,0 & & & & & 3,4 \\
\hline \multicolumn{7}{|c|}{ AREA TEMÁTICA DE INFORMATICA } \\
\hline SIAD & 1,4 & 2 & 1 & 23 & & 2,9 \\
\hline SCINF & 1,4 & & & & & 2,9 \\
\hline \multicolumn{7}{|c|}{ AREA TEMÁTICA DE PRODUÇAOO AGRICOLA E ANIMAL } \\
\hline ZG & 4,0 & 2 & - & 24 & & 3,0 \\
\hline NA & 2,2 & 2 & - & 24 & & 3,0 \\
\hline SC PAA & 3,1 & & & & & 3,0 \\
\hline \multicolumn{7}{|c|}{ ÁREA TEMÁTICA DE TECNOLOGIA VETERINÁRIAA } \\
\hline CAEL & 1,9 & 1 & - & 20 & 5 & 3,4 \\
\hline BAC & 2,1 & 3 & - & 23 & & 3,1 \\
\hline VCCA & 2,9 & 1 & - & 24 & 1 & 3,4 \\
\hline MCD & 1,9 & 2 & - & 22 & 2 & 3,4 \\
\hline SPV & 3,0 & 1 & - & 24 & 1 & 3,4 \\
\hline SC TEV & 2,4 & & & & & 3,3 \\
\hline SC & $\sqrt{1,5}$ & & & & & 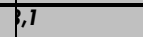 \\
\hline
\end{tabular}




\section{Egitania}

s c i e $\Omega$ c i a

Tabela 10 - A Sustentabilidade curricular do curso de Enfermagem Veterinária estruturada com base nas unidades curriculares

Notas: Não estão aqui representadas as respostas dos docentes porque a informação subjacente não foi ordenada por unidade curricular, para preservar o anonimato dos mesmos. Unidades curriculares: ANATAnatomia, EBEA-Etologia e Bem-Estar Animal, FIS I-Fisiologia I, MI-Microbiologia e Imunologia, ZG-Zootecnia Geral, BF-Biofísica, BQ-Bioquímica, FIS II-Fisiologia II, GENET-Genética, HAP-Histologia e Anatomopatologia, CAEL-Colheita de Amostras e Envio ao Laboratório, EBFES-Ecologia e Biologia da Fauna Exótica e Silvestre, IFA-Introdução à Farmacologia e Anestesiologia, NA-Nutrição Animal, RO-Reprodução e Obstetrícia, BACBioquímica e Análises Clínicas, DICPPL-Doenças Infeto-Contagiosas e Parasitárias e Práticas de Laboratório, EV-Enfermagem Veterinária, SIAD-Sistemas de Informação e de Apoio à Decisão, VCCA-Virologia e Cultura de Células Animais, EL-Ética e 77Legislação, MCD-Métodos Complementares de Diagnóstico, MEA-Morfologia e Estética Animal, OGE-Organização e Gestão da Empresa, SPV-Saúde Pública Veterinária.

É ainda de relevar que, de entre as 25 unidades curriculares, 'Biofísica' é claramente a que mais se afasta dos objetivos e expectativas dos alunos. É a unidade curricular cotada com a menor concordância em 21 questões, entre as quais, 12, com valor médio abaixo de 2,5. Possui no entanto a pontuação média global de 2,49, próxima do valor que separa a concordância da discordância.

Por outro lado, a unidade curricular de 'Ética e Legislação', foi a disciplina que obteve mais vezes (13) o valor máximo de sustentabilidade curricular.

\subsubsection{A Sustentabilidade Curricular de Acordo com Todas as Fontes de Informação}

Finalmente, quando comparados os resultados de todas as fontes de informação utilizadas (alunos, docentes e plano de estudos), a sustentabilidade curricular da licenciatura em Enfermagem Veterinária, corresponde ao valor médio de 2,8, cumprindo satisfatoriamente os pressupostos preconizados pela rede ACES para um currículo sustentável (Tabela 11).

\begin{tabular}{|c|c|c|}
\hline \multicolumn{2}{|c|}{ Fonte de Informação } & $\begin{array}{c}\text { Sustentabilidade } \\
\text { Curricular }\end{array}$ \\
\hline \multicolumn{2}{|c|}{ Secundária } & 2,5 \\
\hline \multirow{2}{*}{ Primária } & Questionários aos alunos & 3,1 \\
\hline & Questionários aos docentes & 2,9 \\
\hline \multicolumn{2}{|c|}{ Sustentabilidade Curricular (média global) } & 2,8 \\
\hline
\end{tabular}

Tabela 11 - A sustentabilidade curricular da licenciatura em Enfermagem Veterinária

\section{CONCLUSÕES E RECOMENDAÇÕES}

Da investigação realizada concluiu-se que, embora a ESAB incorpore matérias de índole ambiental em diversas ciências e seja uma instituição amiga do ambiente (gestão de energia, água e resíduos, projetos EcoESAB e VERCampus, prática de agricultura biológica no seio da academia ), não possui um plano de sustentabilidade curricular ajustado aos conteúdos programáticos dos cursos, que envolva toda a comunidade académica e as instituições parceiras. 


\section{Egitania}

$s$ c i e $\Omega$ c i a

Embora o corpo docente seja sensível ao enquadramento de matérias ambientais relacionadas com as suas áreas científicas, possui algumas dificuldades para cruzar aspetos das áreas da economia, política, civismo, consumo e pobreza com as suas disciplinas. As temáticas referidas são abordadas esporadicamente nas aulas, mas sem um enquadramento planeado com as matérias.

De harmonia com o exposto, observou-se uma visão maioritariamente antropocêntrica e excecionalmente ecocêntrica dos conceitos de Ambiente e EADS. Quanto ao conceito de Ambiente, o ser humano foi colocado no centro - é importante preservar o Ambiente pois dele depende a espécie humana - perdendo-se o valor intrínseco do Ambiente pelo interesse dos elementos e processos que ocorrem naturalmente no equilibrio ecológico do planeta como um todo. Do mesmo modo, na visão redutora de Desenvolvimento Sustentável, foi colocada a ênfase na educação para a defesa e proteção do Ambiente porque dele depende a manutenção da espécie humana, ao invés de se enfatizar a visão sistémica da EADS como um processo coerente de adaptação transversal das temáticas ambientais aos currículos dos cursos, bem como a ênfase numa didática de ensino que estimule os alunos para o pensamento complexo.

De igual modo, no contexto dos alunos, observou-se uma visão incompleta e desorganizada do conceito de Ambiente, reduzindo-o à sua componente natural e aos problemas ambientais. Evidenciaram porém, possuir um conhecimento mais aproximado do conceito de Desenvolvimento Sustentável do que do conceito de Ambiente, relacionando-o com o equilibrio sociedade-Ambiente e a preservação dos recursos naturais, tanto no presente como para as gerações futuras.

No contexto da licenciatura em Enfermagem Veterinária, de acordo com os dois grupos de análise, o ensino-aprendizagem praticado cumpre nove das dez características preconizadas pela rede ACES. Efetuada a triangulação da informação, a ambientalização curricular situou-se no ponto médio de 2,8 (1-4 na escala de Likert), ou seja, 'está presente' a ambientalização curricular no curso. Para os respondentes, as maiores debilidades alocam-se na característica I| 'Ordem disciplinar: flexibilidade e permeabilidade', com uma avaliação negativa (valor médio 2) e a característica com a maior cotação foi a característica VI 'Coerência e reconstrução entre teoria e prática' (valor médio 3,7).

Em relação às disciplinas, individualmente, de entre as 25 unidades curriculares do curso, 'Biofísica' foi claramente a que mais se afastou dos objetivos e expectativas dos alunos, sendo classificada com os menores resultados em 21 questões (12 abaixo de 2,5). De facto, os alunos, para além de não compreenderem qual a importância da 'Biofísica' para a sua formação, também não compreendem claramente qual o enquadramento da mesma com as outras disciplinas do curso.

Assim, na formação das futuras gerações, a ESAB deverá reforçar a inclusão transversal de critérios e valores de sustentabilidade na sua oferta formativa, estruturados com base em paradigmas interdisciplinares, e, no âmbito da licenciatura em Enfermagem Veterinária, será necessário aperfeiçoar o processo de ensino-aprendizagem da unidade curricular de 'Biofísica'. Finalmente, o corpo docente deverá reforçar a sua formação ambiental nas áreas onde 


\section{Egitania}

s c i e $\Omega$ c i a

considerar estar menos preparado, segundo os paradigmas da Educação para o Desenvolvimento Sustentável.

\section{REFERÊNCIAS}

Barrón, A.; NAvarrete, A.; Ferrer-Balas, D. (2010). Sostenibilización Curricular en las Universidades Españolas. ìHa Llegado la Hora de Actuar? ReVISta Eureka sobre Enseñanza y Divulgación de las Ciencias. Asociación de Profesores Amigos de la CienCia-EUReKa, 7 , No EXTRAORDINARIO, 388-399.

Barth, M.; Godemann, J.; RieCKmann, M.; Stoltenberg, U. (2007). DeVeloping Key Competencies for Sustainable Development in Higher EdUCATION. INTERNATIONAL JOURNAL OF SUSTAINABILITY IN HIGHer EdUCATION, 8 (4), 416-430.

Bodelón, F. (1980). La Calidad de Vida y el Derecho. la Calidad de Vida en el Proceso de Humanización. AselCA y Asitema

Cachapuz, A.; Martins, F.; Pinho, L. (2003). Adequação das Características de ambientalização ao Curso de licenciatura em Planeamento Regional e Urbano da Universidade de Aveiro/Portugal. 2. Proceso de Caracterización de la Ambientalización Curricular de los Estudios Universitarios. Ed. Univ. Girona. Red ACES. Vol.2, 215-232.

Couto, A.; Alves, M.; CARVAlho, P.; MAtos, A. (2006). Universidade e Transdisciplinaridade na Transição para a Sustentabilidade: Uma análsie Exploratória. In: Wulf, C. e Newton, B. (eds.). Desarrollo Sostenible. European Studies in Education. Berlin, (22), $101-119$.

Couto, A.; Alves, M.; Matos, A.; Carvalmo, P. (2005). Universidade NA Transição para a Sustentabilidade: TendênCias, EstratéGIAS E Práticas. In III Seminário Internacional. Rede Alfa PLANGIES. Univ. NaCional da Costa Rica. Costa Rica.

Couto, A.; Matos, F.; Carvalho, P.; Céu, M. (2004). Ciência, Inovação e Desenvolvimento Sustentável: Desafios e Implicações Estratégicas para a Universidade. In 2॰ Seminário internacional Alfa PlangIES. Universidade da Beira Interior. Covilhã. Portugal, 25-29 DE OUTUBRO.

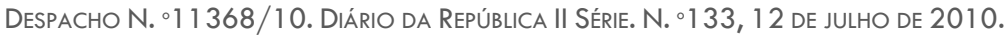

Fernandes, A.; Gonçalves, F.; Pereira, M.; Azeitelro, U. (2007) Educação Ambiental: Características, Conteúdos, Objectivos e actividades Práticas. O Caso Português. In Gonçalves, F.; Pereira, R.; Azeitelro, U.; Pereira, M.J. (eds.). Actividades Práticas em ClênCIAS e EduCaÇÃo Ambiental. Ed. InStituto Piaget. Lisboa, 11 -4 1.

Fouto, A. (2002). O Papel das Universidades Rumo ao Desenvolvimento Sustentável: Das RelaçÕes Internacionals Às Práticas locals. Mestrado em Gestão e Políticas AmbientaIs. Relações InternaCionais do Ambiente. Universidade Nova de Lisboa. Lisboa.

Gel, A.; Junyent, M.; Sánchez, S. (2003). Ambientalización Curricular de los Estudios Superiores. 3. Diagnóstico de la Ambientalización Curricular de los Estudios Superiores. Ed. Universidad de Girona. Red ACES. Vol 3.

Geli, A.; Junyent, M.; SánChez, S. (eds.) (2004). Ambientalización Curricular de los Estudios Superiores. 4. Acciones de Intervención y Balance final del Proyecto. Ed. Univ. Girona. Red ACES. Vol.4.

Hidalgo, D. (2007). Otra Mirada a la Educación para la Sostenibilidad en el Entorno Universitario. Centro nacional de Educación AMBIENTAL. ESPAÑA.

Júnior, W.; Gargallo, J; Amorim, A.; Bau, E. (2003). As 10 Características em um Diagrama Circular. 2. Proceso de Caracterización de la Ambientalización Curricular de los Estudios Universitarios. Ed. Univ. Girona. Red ACES. Vol.2, 35-55.

Junyent, M.; Gell, A.; Arbat, E. (eds.) (2003). Ambientalización Curricular de los Estudios Superiores. 2. Proceso de Caracterización de la Ambientalización Curricular de los Estudios Universitarios. Ed. Univ. Girona. Red ACES. Vol.2.

Madeira, A. (2008). Indicadores de Sustentabilidade para Instituições do Ensino Superior. DissertaÇão de Mestrado em Ambiente. FACULDADE DE ECONOMIA DA UNIVERSIDADE DO PORTO. PORTO.

Marcomin, F. \& Silva, A. (2009). RefleXões Académicas. A Sustentabilidade no Ensino Superior Brasileiro: Alguns Elementos a PartiR da Prática da Educação Ambiental na Universidade. Contrapontos. Itajaí, 9 (2), 104-1 17. 


\section{Eqgitania \\ $s$ c i e $\Omega$ c i a}

Martínez, A. (2008). La Conciencia Ambiental como Herramienta para la Educación ambiental: Conclusiones y Reflexiones de un Estudio en el Ámbito Universitario. Centro Nacional de Educación Ambiental. España.

Martins, F.; Cachapuz, A.; Pinho, L. (2003). Diagnóstico do Grau de ambientalização Curricular: Curso de licenciatura em Planeamento Rural e Urbano da Universidade de Aveiro (Portugal). 3. Diagnóstico de la Ambientalización Curricular de los Estudios SUPERIORES. ED. UNIV. GIRONA. RED ACES. VOL.3, 307-333.

Matos, A. (2014) A Sustentabilidade CurRicular da Licenciatura em Enfermagem Veterinária da Escola Superior Agrária de Bragança - Portugal. Tese de Doutoramento em Educação ambiental. Universidade de Salamanca. Espanha.

Minguet, P. \& Solís, M. (2009). La Formación de Competencias Básicas para el Desarrollo Sostenible: El Papel de la Universidad. ReVISTA DE EDUCACIÓN, NºXTRAORDINARIO, 219-237.

Murga-Menoyo, M. (2013). Desarrollo Sostenible: Problemáticas, Agentes y Estrategias. McGraw-Hill. Uned. Madrid.

pNud (1997). Programa das Nações Unidas para o Desenvolvimento. Gestión ambiental Urbana para Organismos no Gubernamentales de America Latina.

RAIPB-ESA (2011). RELATÓRIO de ACtIVIDADES. ESCOLA SUPERIOR AGRÁRIA. INSTITUTO POLITÉCNICO de BRAGANÇA.

Ramón, l. (1981). Ideas ACerCa de la Intervención Administrativa sobre el Medio Ambiente. Derecho Administrativo, №190. ABRIL/JUNHO.

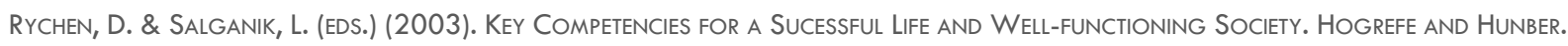
CAMBRIDGE.

Un (2001). United nations. Commission on Sustainable development theme indicator framework from 2001. WWW.UN.ORG/ESA/SUSTDEV/NATLINFO/INDICATORS/ISDMS2001/TABLE_4.HTM (ACEDIDO EM 25/06/2012).

Unesco (1978). United Nations Educational, SCientific and Cultural Organization. Conferéncia Intergovernamental sobre EDUCACIÓN AMBIENTAL. TBILISSI (URSS). INFORME FINAL. PARIS.

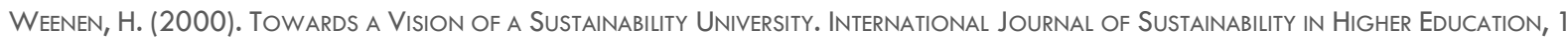
(1), 20-34.

Yunén, R. (1995). Anotaciones Conceptuales sobre DereCho Ambiental. Santo Domingo. República dominicana. 


\section{Anexo}

MÉDIAS PONDERADAS LIKERT

\section{Frequências}

\begin{tabular}{|c|c|c|c|c|c|c|c|c|c|c|c|c|c|c|c|c|c|c|c|c|c|}
\hline \multicolumn{2}{|r|}{ QUESTÕES } & $\begin{array}{c}\text { No início } \\
\text { do } \\
\text { semestre } \\
\text { o } \\
\text { professor } \\
\text { faz umaa } \\
\text { análise } \\
\text { histórica } \\
\text { e } \\
\text { epistemol } \\
\text { ógica das } \\
\text { disciplina } \\
\text { s } \\
\text { enquadra } \\
\text { ndo-as no } \\
\text { curso e } \\
\text { relaciona } \\
\text { ndo-a } \\
\text { com as } \\
\text { outras } \\
\text { disciplina } \\
\text { s }\end{array}$ & $\begin{array}{c} \\
\text { o } \\
\text { profess } \\
\text { or na } \\
\text { sala de } \\
\text { aula } \\
\text { transm } \\
\text { ite uma } \\
\text { forma } \\
\text { comple } \\
\text { xa de } \\
\text { ver o } \\
\text { mundo }\end{array}$ & $\begin{array}{c}\text { As } \\
\text { disciplin } \\
\text { as do } \\
\text { curso } \\
\text { mostra } \\
\text { m que } \\
\text { existe } \\
\text { uma } \\
\text { visão } \\
\text { dinâmic } \\
\text { a dos } \\
\text { fenóme } \\
\text { nos e } \\
\text { situaçõe } \\
\text { s } \\
\text { ocorrida } \\
\text { s no } \\
\text { planeta }\end{array}$ & $\begin{array}{c}\text { p } \\
\text { professo } \\
r \text { nas } \\
\text { aulas } \\
\text { dedica } \\
\text { algum } \\
\text { tempo } \\
\text { ao } \\
\text { debate } \\
e \\
\text { estimula } \\
\text { a } \\
\text { atitude } \\
\text { crítica e } \\
\text { construt } \\
\text { iva dos } \\
\text { alunos } \\
\text { de } \\
\text { forma } \\
\text { explíita }\end{array}$ & $\begin{array}{c}\text { As } \\
\text { disciplin } \\
\text { as do } \\
\text { curso } \\
\text { estimula } \\
\mathrm{m} \text { a } \\
\text { imaginaç } \\
\text { ão e a } \\
\text { criativid } \\
\text { ade dos } \\
\text { alunos, } \\
\text { incentiva } \\
\text { ndo-os a } \\
\text { rever } \\
\text { várias } \\
\text { interpret } \\
\text { ações e } \\
\text { soluções } \\
\text { para os } \\
\text { problem } \\
\text { as reais }\end{array}$ & $\begin{array}{c}\text { Nas } \\
\text { minhas } \\
\text { disciplin } \\
\text { as } \\
\text { particip } \\
\text { am } \\
\text { profissio } \\
\text { nais e } \\
\text { instituiç } \\
\text { ôes } \\
\text { sociais } \\
\text { exterior } \\
\text { es à } \\
\text { ESAB } \\
\text { em } \\
\text { áreas } \\
\text { disciplin } \\
\text { ares e } \\
\text { não } \\
\text { disciplin } \\
\text { ares }\end{array}$ & $\begin{array}{c}\text { O } \\
\text { professor } \\
\text { na sala } \\
\text { de aula } \\
\text { aborda } \\
\text { problemá } \\
\text { ticas de } \\
\text { outras } \\
\text { áreas de } \\
\text { conhecim } \\
\text { ento } \\
\text { (sociais, } \\
\text { culturais, } \\
\text { económic } \\
\text { as, } \\
\text { tecológi } \\
\text { cas, } \\
\text { ambienta } \\
\text { is...) a } \\
\text { nivel } \\
\text { local e } \\
\text { global }\end{array}$ & $\begin{array}{c}\text { No } \\
\text { curso } \\
\text { organiza } \\
\text { m-se } \\
\text { eventos } \\
\text { (congres } \\
\text { sos, } \\
\text { semanas } \\
\text { temátic } \\
\text { as...) em } \\
\text { parceria } \\
\text { com } \\
\text { outras } \\
\text { instituiç } \\
\text { ôes }\end{array}$ & $\begin{array}{c}\text { Concord } \\
\text { o com a } \\
\text { forma } \\
\text { como } \\
\text { está } \\
\text { organiza } \\
\text { do o } \\
\text { plano } \\
\text { curricula } \\
\text { r do } \\
\text { curso de } \\
\text { EV }\end{array}$ & $\begin{array}{l}\text { Quando } \\
\text { se } \\
\text { debate } \\
\mathrm{m} \text { ideias } \\
\text { nas } \\
\text { aulas e } \\
\text { fora } \\
\text { delas os } \\
\text { professo } \\
\text { res têm } \\
\text { em } \\
\text { conta a } \\
\text { opinião } \\
\text { dos } \\
\text { alunos }\end{array}$ & $\begin{array}{c}\text { Na sala de } \\
\text { aula o } \\
\text { professor } \\
\text { reforça as } \\
\text { habilidades } \\
\text { sociais } \\
\text { (respeito, } \\
\text { tolerância, } \\
\text { diálogo, } \\
\text { cooperação } \\
\ldots .) \text { e } \\
\text { atitudes de } \\
\text { entreajuda } \\
\text { entre os } \\
\text { alunos, } \\
\text { favorecendo } \\
\text { a realização } \\
\text { de trabalhos } \\
\text { de grupo e } \\
\text { individuais }\end{array}$ & $\begin{array}{c}0 \\
\text { professo } \\
r \\
\text { fomenta } \\
a \\
\text { atividad } \\
e \\
\text { autóno } \\
\text { ma e a } \\
\text { autoesti } \\
\text { ma dos } \\
\text { alunos }\end{array}$ & \begin{tabular}{|c|} 
O \\
professo \\
r adota \\
um \\
discurso \\
e uma \\
postura \\
coerent \\
es com \\
as suas \\
atitudes \\
dentro e \\
fora da \\
sala de \\
aula
\end{tabular} & $\begin{array}{c}\text { O } \\
\text { professo } \\
\text { r na sala } \\
\text { de aula } \\
\text { reflete } \\
\text { explicita } \\
\text { mente } \\
\text { uma } \\
\text { coerênci } \\
\text { a e } \\
\text { articulaç } \\
\text { ão entre } \\
\text { as } \\
\text { compon } \\
\text { entes } \\
\text { teórica e } \\
\text { prática } \\
\text { das } \\
\text { disciplin } \\
\text { as }\end{array}$ & \begin{tabular}{c|} 
Nas \\
aulas \\
reforça- \\
se o \\
trabalho \\
interdisc \\
iplinar \\
para \\
solucion \\
ar os \\
desafios \\
atuais e \\
futuros
\end{tabular} & \begin{tabular}{c|} 
Nas \\
aulas as \\
metodol \\
ogias \\
adotada \\
s são \\
adequad \\
as aos \\
conteúd \\
os \\
curricula \\
res
\end{tabular} & $\begin{array}{c}\text { Nas } \\
\text { aulas } \\
\text { são } \\
\text { utilizada } \\
s \\
\text { metodol } \\
\text { ogias de } \\
\text { reflexão } \\
\text { e } \\
\text { participa } \\
\text { ção para } \\
\text { a } \\
\text { resoluçã } \\
\text { o de } \\
\text { problem } \\
\text { as reais }\end{array}$ & $\begin{array}{c}\text { Nas } \\
\text { aulas os } \\
\text { alunos } \\
\text { participa } \\
\text { m nos } \\
\text { debates, } \\
\text { trabalho } \\
\mathrm{s} \text { de } \\
\text { grupo e } \\
\text { outras } \\
\text { atividad } \\
\text { es }\end{array}$ & $\begin{array}{c}0 \\
\text { professo } \\
\text { rna sala } \\
\text { de aula } \\
\text { promov } \\
e \\
\text { valores } \\
\text { que } \\
\text { motive } \\
\text { mos } \\
\text { alunos a } \\
\text { participa } \\
r \\
\text { ativame } \\
\text { nte na } \\
\text { proteçã } \\
\text { o e } \\
\text { melhori } \\
\text { a do } \\
\text { ambient } \\
\text { e }\end{array}$ & $\begin{array}{c}\text { O curso } \\
\text { prepara-os } \\
\text { alunos para } \\
\text { serem } \\
\text { agentes de } \\
\text { mudança, } \\
\text { contribuind } \\
\text { o para a } \\
\text { melhoria } \\
\text { da } \\
\text { qualidade } \\
\text { ambiental e } \\
\text { qualidade } \\
\text { de vida da } \\
\text { sociedade }\end{array}$ \\
\hline D & \begin{tabular}{|l|l} 
& Valid \\
\end{tabular} & 16 & 16 & 16 & 16 & 16 & 15 & 15 & 15 & 11 & 15 & 15 & 15 & 16 & 16 & 16 & 16 & 16 & 16 & 16 & 16 \\
\hline 0 & Missing & 0 & 0 & 0 & 0 & 0 & 1 & 1 & 1 & 5 & 1 & 1 & 1 & 0 & 0 & 0 & 0 & 0 & 0 & 0 & 0 \\
\hline c & Mean & 2,81 & 2,94 & 2,75 & 3,38 & 2,88 & 1,73 & 2,53 & 2,60 & 2,91 & 3,27 & 3,47 & 3,47 & 3,75 & 3,63 & 3,06 & 3,44 & 3,31 & 2,94 & 2,56 & 2,69 \\
\hline $\mathrm{E}$ & Median & 3,00 & 3,00 & 3,00 & 4,00 & 3,00 & 1 & 3,00 & 3,00 & 3,00 & 3,00 & 4,00 & 4,00 & 4,00 & 4,00 & 3,00 & 3,00 & 3,00 & 3,00 & 3,00 & 3,00 \\
\hline$N$ & Std. Deviation & ,911 & ,680 & ,931 & 806 & 806 & 961 & ,915 & ,910 & ,831 & ,594 & ,640 & ,640 & ,447 & ,500 & ,574 & ,512 & ,704 & ,680 & ,727 & 873 \\
\hline A & \begin{tabular}{|l|l|}
$\mathbf{N}$ & Valid \\
\end{tabular} & 24 & 28 & 27 & 27 & 29 & 26 & 28 & 27 & \begin{tabular}{|l|}
29 \\
\end{tabular} & 28 & 29 & 29 & 29 & 29 & 27 & 29 & 29 & 28 & 29 & 28 \\
\hline L & Missing & 5 & 1 & 2 & 2 & 0 & 3 & 1 & 2 & 0 & 1 & 0 & 0 & 0 & 0 & 2 & 0 & 0 & 1 & 0 & 1 \\
\hline u & Mean & 3,38 & 3,05 & 3,28 & 2,96 & 3,23 & 1,78 & 3,03 & 2,48 & 3,41 & 3,57 & 3,38 & 3,46 & 3,73 & 3,65 & 2,80 & 3,58 & 3,23 & 3,17 & 2,91 & 2,88 \\
\hline $\mathbf{N}$ & Median & 3,00 & 3,12 & 3,28 & 3,20 & 3,36 & 1,58 & 3,10 & 2,52 & 3,48 & 3,60 & 3,44 & 3,48 & 3,88 & 3,72 & 3,00 & 3,60 & 3,60 & 3,16 & 3,12 & 2,92 \\
\hline 0 & Std. Deviation & ,576 &, 545 & ,448 & ,768 & ,559 & 0,687 & ,612 & ,708 & ,371 & ,391 & ,590 & ,489 & ,353 & ,351 & ,933 & 330 & ,830 & ,689 & ,674 & 712 \\
\hline
\end{tabular}

